\title{
De las semillas criollas a las semillas certificadas Maíz y agronomía en Antioquia (1920-1980)*
}

\section{Resumen}

Este artículo expone, a partir de una revisión de archivos regionales, el tránsito de la utilización de semillas criollas a las semillas certificadas de maíz en Antioquia durante el periodo 1920-1980. En este departamento, la tecnificación agrícola estuvo en manos de instituciones oficiales y misiones extranjeras que definieron "modernizar" el campo colombiano con la implementación de la investigación y experimentación agronómica. En este proceso, la renovación de las técnicas de cultivos, en especial el mejoramiento de las semillas de maíz para una mayor producción, ocuparon un espacio significativo. El análisis de documentos provenientes del mundo de la agronomía, combinado con información de fuentes históricas, muestra el desfase entre la experimentación agronómica y la producción de este cereal, alimento insigne de la cultura alimentaria de esta sociedad. El texto muestra los esfuerzos y avances del conocimiento agronómico, pero al mismo tiempo expone su escasa incidencia en el desarrollo rural antioqueño.

\section{Palabras clave}

Autores: Historia rural, agricultura en Antioquia, Revolución Verde, maíz, modernización.

Referencia bibliográfica para citar este artículo: Sibaja Madera, Francisco Javier y Álvarez Múnera, José Roberto. "De las semillas criollas a las semillas certificadas Maíz y agronomía en Antioquia (19201980)". Anuario de Historia Regional y de las Fronteras 26.1 (2021): 153-186.

Francisco Javier Sibaja Madera: Magister en Historia por la Universidad de Antioquia. Investigador del Grupo de Investigación en Historia Social de la Universidad de Antioquia. Código ORCID: 0000-00027177-2126. Correo electrónico: fco.sibaha@gmail.com

José Roberto Álvarez Múnera: Doctor en Ciencias Sociales de la Universidad de Antioquia. Magister en Estudios Políticos de la Universidad Pontificia Bolivariana. Investigador del Grupo de Investigación en Historia Social de la Universidad de Antioquia. Código ORCID: 0000-0003-3550-7015. Correo electrónico: joseroberto.alvarez@upb.edu.co

\footnotetext{
* El artículo es resultado del proyecto de investigación: "Producción y comercialización de maíz en Antioquia, 1950-2010. Empresariales e impacto económico y social", financiada por la Universidad de Antioquia, código CODI 2014-1303.
} 


\title{
From Native Seeds to Certified Ceeds Corn and Agronomy in Antioquia (1920-1980)
}

\begin{abstract}
This article exposes, based on a review of regional archives, the transition from the use of native seeds to certified corn seeds in Antioquia during the 1920-1980 period. In this department, agricultural technology was in charge of official institutions and foreign missions that defined "the modernization" to the Colombian countryside with the implementation of agronomic research and experimentation. In this process, the renewal of cultivation techniques, especially the improvement of corn seeds for greater production, occupied a significant space. The analysis of documents from the world of agronomy, combined with information from historical sources, shows the gap between agronomic experimentation and the production of this cereal, a flagship food of the food culture of this society. The text presents the efforts and advances of agronomic knowledge but at the same time exposes its scarce impact on rural development in Antioquia.
\end{abstract}

Keywords

Thesaurus: Rural History, Agriculture in Antioquia, Green Revolution, Corn, Modernization.

\section{De sementes nativas a sementes certificadas Milho e agronomia em Antioquia (1920-1980)}

\section{Resumo}

Este artigo expõe, com base em uma revisão de arquivos regionais, a transição do uso de sementes crioulas para sementes de milho certificadas em Antioquia durante o período 1920-1980. Neste departamento, a tecnificação agrícola esteve a cargo de instituições oficiais e missões estrangeiras que definiram "a modernização" do campo colombiano com a implementação da pesquisa e experimentação agronômica. Nesse processo, a renovação das técnicas de cultivo, especialmente o beneficiamento de sementes de milho para maior produção, ocupou um espaço significativo. A análise de documentos do mundo da agronomia, misturado com informações de fontes históricas, mostra a falta de relação entre a experimentação agronômica e a produção desse cereal, alimento que representa a cultura alimentar desta sociedade. O texto apresenta os esforços e avanços do conhecimento agronômico, mas ao mesmo tempo expõe seu escasso impacto no desenvolvimento rural de Antioquia.

\section{Palavras-chave}

Thesaurus: História rural, agricultura em Antioquia, Revolução Verde, milho, modernização. 


\section{Introducción}

Desde principios del siglo XX un aspecto capital en las transformaciones técnicas de la agricultura colombiana fue el comienzo de una política tecnológica encaminada hacia la formación de profesionales de la agricultura. ${ }^{1}$ En la historiografía regional predominan estudios que abordan la modernización del campo teniendo en cuenta aspectos como la introducción de maquinaria e insumos agrícolas, acceso a créditos bancarios, la construcción de medios de transportes, ligados principalmente con el desarrollo del cultivo del café. ${ }^{2}$ Sin embargo, poca atención se ha prestado al papel de la investigación científica agrícola, a las facultades de agronomía y ciencias agrarias, las estaciones experimentales y a los agrónomos en la modernización de la agricultura en Colombia. En este sentido, el estudio de las semillas de maíz plantea un punto de referencia clave para analizar el cambio tecnológico y la modernización en la agricultura nacional.

En esta perspectiva, el presente artículo analiza el proceso de tecnificación que experimentó la agricultura de Antioquia entre las décadas de 1920 y 1980 mediante el mejoramiento de las semillas y el cultivo de maíz, llevado a cabo por la articulación de una serie de instituciones y empresas que instauraron la agronomía y la industria de las semillas certificadas, ${ }^{3}$ con el objetivo de reemplazar a las semillas criollas para obtener mayores rendimientos en la producción de este cereal y atender las demandas de los mercados de alimentos y otras industrias como la elaboración de productos concentrados para animales. El artículo ofrece un recorrido explicativo del caso antioqueño, departamento ubicado entre los Andes y las llanuras del Caribe colombiano, que históricamente se ha caracterizado como una sociedad maicera. ${ }^{4}$ Este cereal se ha constituido en componente central en la dieta de los antioqueños, que además de su consumo directo, también lo han empleado en el desarrollo de otros procesos productivos como la ganadería porcina y vacuna. ${ }^{5}$

La experiencia antioqueña hace parte tanto de un contexto nacional e internacional preocupado por la modernización y transformación de las prácticas agrícolas conocido generalmente como Revolución Verde. Si bien es cierto que existe una extensa bibliografía sobre proceso en América Latina, aun no se ha estudiado en detalle algunos aspectos del caso colombiano, particularmente en Antioquia. Esta región, sobre todo su capital Medellín, fue un escenario principal de este proceso debido a la intervención de organismos internacionales como la Fundación Rockefeller (FR).

\footnotetext{
${ }^{1}$ Jesús Antonio Bejarano, "Las técnicas agropecuarias en el siglo XX", Nueva Historia de Colombia (Bogotá: Planeta, 1989) 296.

2 James Henderson, La modernización en Colombia. Los años de Laureano Gómez, 1889-1965 (Medellín: Editorial Universidad de Antioquia, 2006) 14,167.

3 Álvaro Castillo Nieto, La agroindustria procesadora de cereales de Colombia, factores externos e internos inductores de cambio (Tesis doctoral, Universidad Nacional de Colombia-Bogotá, 2020) 81-168.

${ }^{4}$ Jorge Rodríguez, Maizopólis: monografías de los distritos antioqueños (Medellín: Correo Liberal, 1915) Gregorio Gutiérrez González, Canto al maíz (Medellín: Colegio Académico de Antioquia, 1957) 26.

${ }^{5}$ Daniel Mesa Bernal, Historia natural del maiz (Bogotá: Litografía de Colombia, 1957) 217-218.
} 
El caso antioqueño ilustra cómo las escuelas, facultades y estaciones experimentales estaban puestas al servicio de la tecnificación agrícola y la producción de semillas con el propósito de incrementar la producción de los principales productos agrícolas. En Antioquia este proceso de tecnificación se concentró en el maíz, un producto de consumo interno; contrario a lo que pasó en programas y estaciones experimentales del Caribe y Centroamérica, las cuales se concentraron en sus productos de exportación. ${ }^{6}$ El resultado de ese proceso fue un nuevo conocimiento que conllevó la formación de un marco institucional y una industria que presentó una significativa oferta de nuevas variedades de un cereal tan vital y arraigado en la sociedad antioqueña.

En pocas palabras, este texto estudia el tránsito que se produce de las semillas criollas a las semillas certificadas, proceso que denota también el tránsito de las formas tradicionales a las formas modernas de producción en el mundo rural antioqueño. Las fuentes empleadas corresponden a los informes del programa agrícola establecido entre la FR y el Ministerio de Agricultura de Colombia, correspondencia entre la FR y la Escuela de Agricultura Tropical y la Facultad Nacional de Agronomía de Medellín. Asimismo, son utilizadas documentos de agronomía como resultados de investigaciones, artículos y experimentos publicados por los agrónomos y las estaciones experimentales. Así pues, el texto en primer lugar aborda el proceso de instauración de la agronomía en Antioquia en el contexto de la Revolución Verde en América Latina. Luego, se concentra en las semillas criollas y su importancia para la agricultura y la agronomía. En tercer lugar, examina el proceso de producción de semillas certificadas en las estaciones experimentales de Antioquia. En cuarto lugar, muestra la génesis de la industria de las semillas certificadas; $y$, en quinto lugar, las contradicciones en el uso las semillas certificadas por los agricultores.

\section{Revolución Verde, Fundación Rockefeller y agronomía en Antioquia}

En la década de 1940, el gobierno estadounidense mediante un grupo de fundaciones e instituciones estableció un modelo de modernización de la agricultura basado en la promoción de las ciencias agropecuarias, la generación de nuevas tecnologías como las semillas híbridas y la aplicación de nuevas prácticas agronómicas en varios países de América Latina. ${ }^{7}$ Este proceso de modernización hace parte de un marco más amplio conocido como Revolución Verde; la cual puede entenderse como un proceso de cambio tecnológico no solo en Latinoamérica sino en un contexto global que se extiende hasta Asia y África. Asimismo, puede abordarse como una estrategia de posicionamiento geo-político de los Estados Unidos en América Latina a partir de la Segunda Guerra Mundial y durante la Guerra Fría. ${ }^{8}$ Sin embargo, en términos

\footnotetext{
${ }^{6}$ Stuart McCook, States of nature: science, agriculture, and environment in the Spanish Caribbean 17601940 (Austin, University of Texas Press, 2002) 1-46.

${ }^{7}$ Mercedes Jiménez, "La fundación Rockefeller y la investigación agrícola en América Latina", Comercio Exterior 40.10 (1990): 968-975.

${ }^{8}$ Wilson Picado, Conexiones de la Revolución Verde. Estado y cambio tecnológico en la agricultura de Costa Rica durante el período 1940-1980, (Tesis doctoral, Universidad de Santiago de Compostela, 2012) 80-107.
} 
generales, la Revolución Verde se refiere al proceso de mejoramiento técnico de la agricultura mediante el empleo de maquinarias, sistemas de riego, semillas mejoradas genéticamente, fertilizantes, insecticidas y nuevas prácticas de cultivos, aplicados especialmente en la producción de maíz y trigo. ${ }^{9}$

Durante esos años, la Revolución Verde había prometido liberar a la humanidad de la plaga del hambre mediante la aplicación de los últimos hallazgos científicos y tecnológicos del saber agronómico. ${ }^{10}$ En este contexto, el gobierno estadounidense aplicó una serie de discursos y prácticas como el conocimiento técnico-científico aplicado a la agricultura para la producción de alimentos. ${ }^{11} E s t e$ proceso fue materializado por la FR, una organización filantrópica privada, creada bajo los principios de combatir el hambre, promover la educación, la salud y la higiene en América Latina. ${ }^{12}$ Sin embargo, es importante señalar que la intención de la FR fue más allá de un espíritu exclusivamente filantrópico. Tras ese discurso respaldado en criterios científicos, también sobresale su interés por el control de patentes, el comercio y mercantilización de semillas, la expansión de empresas agroquímicas y entidades financieras estadounidenses; además de influir en las políticas agrarias y en la estabilidad política de los países latinoamericanos.

En esta perspectiva, la trayectoria del Programa de Ciencias Agrícolas de la FR inició en México en $1943,{ }^{13}$ luego se extendió a Colombia y Chile, posteriormente a Costa Rica y Guatemala. ${ }^{14}$ El programa colombiano fue el segundo establecido en América Latina y se constituyó en un importante referente en la apertura de los programas agrícolas de Chile y Centroamérica. En el Valle del Cauca, la principal zona azucarera de Colombia, desde principios de la década de 1940, la FR asesorada por el sociólogo T. Lynn Smithcomenzó un proyecto de mejoramiento de la agricultura mediante la experimentación e investigación agronómica en estaciones experimentales en Palmira, con el propósito de formar una clase media agrícola en esta región del

\footnotetext{
${ }_{9}^{9}$ Mario Cerutti, "Trigo y Revolución Verde en el noroeste de México, 1930-1970", Mundo Agrario 20.43 (2019): 1-21.

${ }^{10}$ Mario Arango Marín, "La revista Facultad Nacional de Agronomía de Medellín como indicador del fraccionamiento especializado del saber agronómico", Revista Facultad Nacional de Agronomía 58.2 (2005): 2801-2811.

${ }^{11}$ Arturo Escobar, La invención del tercer mundo. Construcción y deconstrucción del desarrollo (Caracas: Fundación Editorial El Perro y la Rana, 2007) 20, 179-180.

12 Diana Méndez, "Semillas en tránsfuga. La Fundación Rockefeller en Colombia: escenarios de la Revolución Verde en América Latina, 1950-19672”, Pacarina del Sur 29 (2016): 10.

${ }_{13}$ Josep Cotter, “The Rockefeller Foundation's Mexican agricultural project. A cross-cultural encounter, 1943-1949", en Cuento Marcos (ed.) Missionaries of science: the Rockefeller Foundation and Latin America (Bloomington: Indiana Univerity Press, 1994) 97-125.

${ }^{14}$ Fernando Quesada, "Desidia estatal y diplomacia filantrópica: el Programa Agrícola de la Fundación Rockefeller en Chile, 1940-1970”, en J. Morales (Comp.) Filantropía, ciencia y universidad. Nuevosaportes y análisis sociohistóricos sobre la diplomacia académica en América Latina (Santiago de Chile, Ediciones UCSH, 2018) 185-219. Diana Méndez, El programa Cooperativo Centroamericano para el mejoramiento del maiz: una historia transnacional de la Revolución Verde desde Costa Rica y Guatemala, 1954-1063, (Tesis de Maestría, Instituto de Investigaciones Dr. José María Luis Mora, 2018) 231.
} 
país. ${ }^{15}$ En el departamento de Antioquia la FR también brindó apoyos financieros y técnicos para diversos proyectos, entre los que se destaca el establecimiento de una facultad de agronomía y la organización de una red de centros de investigación para el mejoramiento de las semillas y cultivos de los principales productos alimenticios de Colombia.

En 1947 un grupo de agrónomos colombianos visitaron México, país que era la punta de lanza del proyecto agronómico estadounidense, y observaron los servicios que la FR prestaba en beneficio de la agricultura mexicana y manifestaron el "interés de Colombia para el establecer una unidad agrícola similar que atendiera algunas campañas de investigación como las del mejoramiento de semillas de maíz, trigo y papa". ${ }^{16}$ En 1949, después de una serie reuniones entre los delegados de la FR y representantes del Ministerio de Agricultura, se firmaron los términos finales del convenio de "Unidad Agrícola" para desarrollar programas de investigación con el "objetivo de mejorar y aumentar la calidad de las cosechas básicas en la alimentación del pueblo colombiano, mediante estudios e investigaciones sobre genética, suelos, fitopatología y entomología". ${ }^{17}$ De esta manera, la Facultad Nacional de Agronomía (FNA) de Medellín tuvo una participación significativa en la modernización de la agricultura colombiana como sede principal de una serie de políticas y programas de enseñanza e investigación agrícola encaminados hacía el mejoramiento de la producción de los principales cultivos nacionales.

Esta facultad, creada en 1934 con base en la antigua Escuela de Agricultura Tropical y Veterinaria de Medellín, tenía como objetivo proporcionar conocimientos teóricos y prácticos para que los estudiantes propagaran la industria agrícola en todas sus ramas sobre bases técnicas. ${ }^{18}$ La FR concentró sus actividades en las oficinas, laboratorios y campos de la facultad de Medellín. ${ }^{19}$ En 1950 las primeras actividades realizadas en el marco del convenio agrícola fueron:

En el laboratorio de fitopatología, donde se han concentrado en estudiar las enfermedades de los dos principales cultivos que constituyen la base de la alimentación del pueblo antioqueño: el maíz y el frijol. Estos trabajos de investigación se han venido adelantando en cooperación con los técnicos de la FR y se busca obtener variedades de maíz y frijol resistentes a las principales enfermedades de estos cultivos. También en el laboratorio de Entomología se han venido estudiando las plagas principales de los cultivos y granos

\footnotetext{
${ }^{15}$ Timothy Lorek, "Imagining the Midwest in Latin America: Us advisors and the envisioning of an agricultural middle class in Colombian's Cauca Valley, 1943-1946", The Historian 75.2 (2013): 283-305.

16 "Conferencia del Ministerio de Agricultura y sus asociados con los representantes de las instituciones W.K. Kellogg, Fundación Rockefeller y la Universidad de Michigan”, New York, 18 de noviembre de 1953. AHUNM, Fondo Decanatura, Caja 67, ff. 1-17.

${ }^{17}$ Memorias del Ministerio de Agricultura al Congreso Nacional, 1957-1958 (Bogotá: Imprenta Nacional, 1958) 78.

${ }^{18}$ María Saavedra et al., Facultad de Ciencias Agropecuarias: 90 años sembrando futuro, 1914-2004 (Medellín: Universidad Nacional de Colombia, 2004) 36-40.

${ }^{19}$ Carlos Madrid, "Informe del decano de la FNA al rector de la Universidad Nacional". AHUNM, Fondo Decanatura, Caja 67, ff. 983-986.
} 
almacenados; también se han hecho algunos ensayos experimentales con insecticidas y matamalezas. ${ }^{20}$

La FNA también se convirtió en un importante centro de formación de profesionales de la agricultura. En 1953 representantes del Ministerio de Agricultura y los delegados de la Misión Kelloggs, FR y la Universidad de Michigan se reunieron para "concertar la cooperación de estas instituciones con el gobierno colombiano para el desarrollo de la educación agrícola del país". ${ }^{21}$ Ese mismo año, comenzaron a llegar los primeros profesores procedentes del Michigan State College para implementar los planes de estudios y currículos en la formación de técnicos y agrónomos colombianos. ${ }^{22}$ Asimismo, la Fundación otorgó becas de especialización en universidades de los Estados Unidos para que el personal colombiano se capacitara en investigación y en docencia agrícola. ${ }^{23}$ Los funcionarios del Ministerio de Agricultura y la FR consideraban que el progreso de la agricultura nacional "dependerá de un mayor grupo de agrónomos entrenados y dedicados a la investigación constante de los mejores métodos para aumentar y hacer más eficiente la producción de los cultivos." 24

Así pues, muchos de los primeros ingenieros agrónomos de la FNA se especializaron en el mejoramiento de las semillas de maíz. Un caso ilustrativo en la agronomía antioqueña es el de Eduardo Chavarriaga Misas, egresado de la FNA en la década de $1930 .{ }^{25}$ Era reconocido por ser uno de los primeros mejoradores de maíz en Colombia; y porque fue investigador invitado de la FR en México. ${ }^{26}$ Este profesional se especializó en genética y realizó estudios en Venezuela becado por la FR. ${ }^{27}$ En el Instituto de Agricultura de Caracas trabajó en el mejoramiento genético de plantas de importancia económica tanto para Venezuela como para la mayoría de los países suramericanos. ${ }^{28} \mathrm{Al}$ regreso de esta estancia investigativa, introdujo unas de las primeras semillas mejoradas de maíz en Colombia, la variedad conocida como "Venezuela 1 amarillo"; ${ }^{29}$ además fue profesor en la misma facultad entre las décadas de 1950 y $1960 .{ }^{30}$

\footnotetext{
${ }^{20}$ Carlos Madrid, "Informe del decano de la FNA al rector de la Universidad Nacional". AHUNM. Fondo Decanatura, Caja 67, ff. 983-986.

21 "Memorándum sobre la educación agrícola en Colombia presentado por las instituciones Kellogg y Rockefeller al Ministerio de Agricultura de Colombia”, Medellín, 18 de enero de 1954. AHUNM, Fondo Decanatura, Caja 43, ff. 1-8.

${ }^{22}$ Eduardo Mejía Vélez, "Carta del decano de la FNA al rector de la Universidad Nacional”, Medellín, 23 de mayo de 1953. AHUNM, Fondo Decanatura, Caja 67, sin número de folio.

23 “Antecedentes sobre el convenio de cooperación agrícola entre el gobierno de Colombia y la Fundación Rockefeller", Medellín, 7 de diciembre de 1956. AHNUM, Fondo Decanatura, Caja 67, ff. 1-5.

${ }^{24}$ Ministerio de Agricultura, "III Informe sobre el progreso del Programa Cooperativo entre el Ministerio de Agricultura y la Fundación Rockefeller”, Revista Nacional de Agricultura 587 (1954): 3.

${ }^{25}$ Saavedra et al. 106.

${ }^{26}$ Picado 189.

${ }^{27}$ Norma Johnson, "Carta de la Fundación Rockefeller a la Decanatura de la FNA", New York, 4 de mayo de 1943. AHUNM, Fondo Decanatura, Caja 39, f. 210.

${ }^{28}$ R. Pinto Salavarrieta et al., "Carta a la Decanatura de la FNA", Caracas, 15 de septiembre de 1943. AHUNM, Fondo Decanatura, Caja 39, f. 314.

${ }^{29}$ Hernán Ramírez, "Estudio estadístico comparativo sobre dos variedades de maíz", Revista Facultad Nacional de Agronomía 6.24 (1946): 376.

${ }^{30}$ Ministerio de Agricultura, "II Informe sobre el progreso del Programa Cooperativo entre el Ministerio de
} 
En este sentido, la agricultura colombiana recibió un impulso por efecto de la formación de agrónomos y su convicción de los beneficios que su saber tenía en el progreso de la industria agrícola. ${ }^{31}$ Estos profesionales, formados en sus inicios en escuelas norteamericanas y con experiencia en los programas agrícolas centroamericanos, constituyeron un núcleo de investigación y enseñanza en las facultades de agronomía de Medellín y Valle del Cauca; cualificaron a otro grupo de técnicos y profesionales locales en las estaciones experimentales situadas en diferentes zonas del país, donde la tarea era obtener "nuevas semillas con características superiores a las de cultivo común, mediante el auxilio de la genética aplicada, conocidas como variedades mejoradas y semillas híbridas". ${ }^{32}$

Llegados a este punto es importante resaltar que las semillas mejoradas se tratan de un término ajustado al criterio de optimización genética de una variedad que por lo demás, solo acepta la aplicación controlada de determinados insumos, para que alcance mayores niveles de rendimientos productivos en un contexto ambiental específico. ${ }^{33}$ Es decir, que las variedades mejoradas e híbridas no eran exactamente mejores semillas que las nativas, sino especies adaptadas a un proceso especifico de producción. No obstante, esta narrativa supone una superioridad de unas semillas adaptadas a unas condiciones climáticas, biológicas y de suelos que descalifican, invalidan o descartan otras semillas para su comercialización y uso. Esto conlleva, por un lado, el control del mercado de semillas, y por el otro, el riesgo de la pervivencia de una gran variedad de semillas nativas americanas. ${ }^{34}$

\section{Diversidad de maíz criollo en Antioquia}

A principios del siglo XX en el departamento de Antioquia empleaban una significativa variedad de razas criollas. ${ }^{35}$ En 1907 los habitantes de Medellín y sus alrededores cultivaban y consumían "maíz capio, montaña y maíz indio, con el cual se fabricaba la arepa". ${ }^{36}$ En 1913 el fundador de la Sociedad Antioqueña de Agricultores, Tulio Ospina, identificó otras variedades de semillas que se cultivaban en diferentes zonas del departamento como el "maíz de arado, Cuba de grano duro, maíz de Abejorral (municipio de Antioquia), maíz Chocó, indicado para clima lluvioso por su capacho

\footnotetext{
Agricultura y la Fundación Rockefeller”, Revista Nacional de Agricultura 585 (1952): 34-35.

${ }^{31}$ Eduardo Chavarriaga Misas. "Maíz ETO, una variedad producida en Colombia”, Revista ICA 1.1 (1996) 5.

${ }^{32}$ Las semillas híbridas son el resultado del cruce tanto natural como genético de dos o más variedades de semillas y plantas de maíz. Memorias del Ministerio de Agricultura al Congreso Nacional, 1957-1958 (Bogotá: Imprenta Nacional, 1958) 82.

${ }^{33}$ Picado 65-66.

${ }^{34}$ Helen Curry, "From working collections to the World Germplasm Project: agricultural modernization and genetic conservation al the Rockefeller Foundation", History and Philosophy of the Life Sciences, 39.5 (2017): 1-20.

${ }^{35}$ Las semillas criollas corresponden a las variedades comunes o nativas con orígenes indígenas y campesinos, producidas con técnicas y prácticas agrícolas tradicionales. Raza es el nombre científico de las semillas criollas; en Colombia las razas son de origen primitivo, introducidas e híbridas de polinización natural. L.M. Roberts et al. Razas de maiz en Colombia, p. 132.

${ }^{36}$ Joaquín Antonio Uribe, "Climatología", Anales de la Academia de Medicina de Medellín 9-11 (1907) 161-164.
} 
fuerte, Yucatán de mazorca grande (origen centroamericano), maíz bogotano y maíz amarillo de montaña". ${ }^{37}$ Las exposiciones agropecuarias de 1923 y 1926 en Medellín también revelan nombres y características de las variedades criollas o "regionales" que utilizaban los agricultores antioqueños. En los eventos de esos años premiaron a los cultivadores con las mejores muestras seleccionadas de "maíz fino, montaña, capio, ladera, Cuba y un premio especial para la muestra de maíz pira". ${ }^{38}$

Esta diversidad maicera fue confirmada por la dirección científica de la FR en Colombia a cargo del experto en maíz Lewis M. Roberts; quien había trabajado junto a Paul C. Mangelsdorf en México. ${ }^{39}$ En 1957 Roberts en compañía de los estadounidenses W.H. Hatheway, D.L. Smith y el agrónomo colombiano Ricardo Ramírez, publicaron el libro Razas de maíz en Colombia, donde registraron el origen, características y distribución geográfica de las variedades empleadas por los indígenas y campesinos antioqueños(Tabla 1). ${ }^{40}$ Este libro, producto del programa agrícola de la FR en el país, hizo parte de un proyecto latinoamericano que integro a Colombia con México, Brasil y Centroamérica. El proyecto era el "Comité de Preservación de Variedades Indígenas de Maíz” (CPVIM), el cual tenía un doble objetivo: evitar la extinción de las variedades nativas vulnerables frente a la convivencia con las semillas hibridas, y utilizar el material genético de las razas criollas o indígenas como materia prima para el mejoramiento y la producción de nuevas semillas. Los resultados de este proyecto fueron publicados en una serie de libros titulados Races of Maize con volúmenes dedicados a México, Cuba, Brasil y los países de América Central. ${ }^{41}$ En este sentido, Medellín y el departamento de Antioquia, debido a su diversidad, se convirtieron en uno de los centros de recolección, clasificación y preservación de maíz en América Latina.

\footnotetext{
${ }^{37}$ Víctor Manuel Patiño. Plantas cultivadas y animales domésticos en América Equinoccial -Tomo II(Cali: Imprenta Departamental, 1964) 116-117. Es importante mencionar que Patiño, reconocido agrónomo colombiano, trabajó para la FR en la recolección y clasificación de semillas criollas en el proyecto del CPVIM en la zona Andina.

38 Sociedad Antioqueña de Agricultores, Segunda Asamblea Agraria de Antioquia y Exposición Agropecuaria y de Maquinaria Agrícola (Medellín: Imprenta Oficial, 1926) 1, 25.

${ }^{39}$ Picado 178-179.

${ }^{40}$ Este libro también fue publicado en inglés en los Estados Unidos por el National Research Council de la National Academy of Sciences el mismo año.

${ }^{41}$ Méndez, El Programa Cooperativo Centroamericano, 54-60.
} 
Tabla 1. Razas de maíz criollo en Antioquia a mediados de siglo XX

\begin{tabular}{|c|c|c|c|c|}
\hline NOMBRE & COLOR & LUGAR DE CULTIVO & ALTURA & CLIMA \\
\hline Montaña & $\begin{array}{c}\text { Amarrillo/ } \\
\text { Blanco }\end{array}$ & Oriente Antioqueño & $1.600-2.600$ & $\begin{array}{c}\text { Frío } \\
\text { Moderado }\end{array}$ \\
\hline Capio & $\begin{array}{c}\text { Amarillo/ } \\
\text { Blanco }\end{array}$ & Oriente/Suroeste Antioqueño & $2.100-2.400$ & Frío \\
\hline Amagaceño & $\begin{array}{l}\text { Amarillo/ } \\
\text { Blanco }\end{array}$ & Valle de Aburrá/Suroeste & 1.500.2.500 & $\begin{array}{l}\text { Frío/ } \\
\text { Medio }\end{array}$ \\
\hline Maíz Dulce & Amarillo & Valle de Aburrá/Oriente & $1.200-2.500$ & $\begin{array}{l}\text { Frío/ } \\
\text { Medio }\end{array}$ \\
\hline Puya & $\begin{array}{c}\text { Amarrillo/ } \\
\text { Blanco }\end{array}$ & Urabá/Magdalena Medio & $0-500$ & Caliente \\
\hline Común & $\begin{array}{c}\text { Amarillo/ } \\
\text { Blanco }\end{array}$ & Valle de Aburrá/Occidente & $800-1.400$ & Medio \\
\hline Costeño & $\begin{array}{c}\text { Amarillo/ } \\
\text { Blanco }\end{array}$ & Urabá/Bajo Cauca & $0-800$ & Caliente \\
\hline Yucatán & Blanco & Valle de Aburrá & $500-1.000$ & $\begin{array}{c}\text { Caliente/ } \\
\text { Medio }\end{array}$ \\
\hline Chococeño & Negro/Rojizo & Occidente/Urabá & $0-500$ & Caliente \\
\hline
\end{tabular}

Fuente:L.M. Roberts et al.,Razas de maíz en Colombia (Bogotá: Editorial Máxima, 1957) 132; Víctor Manuel Patiño, Plantas cultivadas y animales domésticos en América Equinoccial -Tomo II- (Cali: Imprenta Departamental, 1964) 92-154.

La variedad de pisos térmicos en Antioquia favoreció la adaptación de distintas razas criollas de maíz. La variedad montaña se encontraba principalmente a lo largo de la Cordillera Central de los Andes; tenía un punto de concentración en Antioquia y otro en el departamento de Nariño, en el sur de Colombia, cultivado en elevaciones con un promedio de $2.000 \mathrm{msnm}$; era empleado sobre todo por agricultores del Oriente antioqueño. El maíz amagaceño, el cual recibe su nombre por el municipio de Amagá en el Suroeste del departamento, era sembrado comúnmente en los alrededores de Medellín y otros lugares de Antioquia sobre todo en la primera parte del siglo XX. ${ }^{42}$ En el Urabá y el Bajo Cauca, situados en los límites con el departamento de Córdoba, los agricultores utilizaban generalmente semillas de raza costeña adecuadas para tierra caliente. La raza puya también era utilizada en altitudes inferiores a los $500 \mathrm{msnm}$, especialmente por los agricultores del Magdalena Medio.

El maíz capio, que era una sub-raza del maíz montaña, la variedad blanca era cultivada en el Oriente antioqueño y la amarilla en Nariño. En Antioquia también utilizaban el "maíz común", el cual era "entre las razas colombianas el mejor con característica agronómicas"; era cultivado en el Valle de Aburrá y en el Occidente del departamento. Ahora bien, muchas de estas razas criollas se cultivaban en una misma

\footnotetext{
${ }^{42}$ Ministerio de Agricultura, "I Informe sobre el progreso del Programa Cooperativo entre el Ministerio de Agricultura y la Fundación Rockefeller”, Revista Nacional de Agricultura 554 (1951): 15-18.
} 
zona, por ejemplo, en el municipio de Urrao, ubicado en el Suroeste antioqueño, cultivaban montaña, amagaceño y chococeño, por su cercanía con el departamento del Chocó. En la década de 1940 el maíz dulce, que se consume actualmente en arepas y tortas de chócolo, apenas se estaba fomentando su cultivo en las tierras de laderas antioqueñas. ${ }^{43}$ Los agricultores en general utilizaron diferentes razas de maíces criollos según las características ambientales, tecnológicas y culturales presentes en las diferentes regiones geográficas y climáticas del departamento.

En el discurso general de la agronomía sobre estas razas de maíz criollo existían dos apreciaciones. La primera se refiere a la importancia de las razas nativas como fuentes genéticas en el proceso de selección y diseño de nuevas variedades, pues las semillas mejoradas, como veremos más adelante, se formaron a partir del cruce de las especies criollas. En este sentido, las razas nativas continuaron ocupando un lugar primario tanto para los agricultores como para los agrónomos fito-mejoradores. De esta manera se puede decir que los especímenes locales cumplieron una función instrumental en la producción de las nuevas semillas de la Revolución Verde. ${ }^{44}$ Sin embargo, algunas variedades criollas como el "maíz común", que era "la raza más popular durante los primeros cincuenta años del siglo XX, estaba siendo reemplazada rápidamente por algunas de las variedades mejoradas". ${ }^{45}$ En vista de esta situación y en el marco del CPVIM fue creado el banco de germoplasma de maíz en la estación Tulio Ospina de Bello en 1952. ${ }^{46}$ Además de este centro de preservación, el Comité estableció uno en la escuela de agricultura de Chapingo en México y otro en Sao Paulo en Brasil. ${ }^{47}$ Estos centros quedaron a cargo de científicos experimentados en el mejoramiento del maíz: genetistas, botánicos y agrónomos vinculados con la FR.48 Estos bancos funcionaban como "una cuenta de ahorros de germoplasma genético para el futuro". ${ }^{49}$

La segunda apreciación señala a las razas criollas como una de las causas principales de la baja productividad del maíz en Colombia. La producción nacional en promedio oscilaba entre 1.000 y $1.100 \mathrm{~kg} / \mathrm{ha}$, cantidad que se encontraba entre los rendimientos más bajos de maíz en el mundo. ${ }^{50}$ Algunos agrónomos consideraban que las variedades criollas utilizadas tradicionalmente por los agricultores "se distinguían por su baja productividad, a más de otras características agronómicas indeseables como plantas de porte alto, demasiado tardías, susceptibles a enfermedades y mediana

\footnotetext{
${ }^{43}$ Carlos Santamaría Sanz, Plan quinquenal de fomento agrícola en Colombia, 1945 (Bogotá: Ministerio de Economía Nacional, 1945) 61-75.

${ }^{44}$ Curry 8-20.

${ }^{45}$ L.M. Roberts et al. 96-98.

${ }^{46}$ ICA, "Banco de germoplasma de maíz", El Correo 54 (Bello), 2 de noviembre de 1969, 7.

${ }^{47}$ Méndez, Programa Cooperativo Centroamericano, 54-60.

${ }^{48}$ Carlos Díaz Amarís et al., Banco Internacional de Germoplasma de Maíz (Bogotá: Boletín de Divulgación -ICA-, 1980) 15-17.

${ }^{49}$ Robert Jugenheimer, Maiz: variedades mejoradas, métodos de cultivo y producción de semillas (México: Limusa, 1988) 161, 653-658.

${ }^{50}$ Guillermo Guerra et al., "Maíz y millo en Colombia: situación actual y perspectivas futuras", Revista Facultad Nacional de Agronomía 25.64 (1966): 18.
} 
prolificidad". ${ }^{51}$ Este era un argumento empleado por la agronomía para justificar el mejoramiento de las variedades nativas y la creación de semillas híbridas. Asimismo, estos agrónomos observaban que los agricultores antioqueños y colombianos hasta mediados del siglo XX estaban:

\begin{abstract}
Al margen de todo el progreso logrado, tanto en herramientas y máquinas como en métodos de cultivo; ignorantes de lo que puede significarles el uso de semillas mejoradas, la siembra a distancias convenientes, la rotación de cosechas, la desyerba mecanizada, el uso de fertilizantes, el combate de plagas y enfermedades. Algunas industrias agrícolas no han logrado romper la barrera de la rutina ancestral, por lo tanto, no es extraño que los rendimientos sean bajos. $^{52}$
\end{abstract}

Como se puede observar, el discurso general de la agronomía y la FR planteaba que el uso de semillas criollas y las prácticas de cultivos inadecuadas, eran uno de los factores causantes de la baja productividad en la agricultura maicera. ${ }^{53} \mathrm{La}$ FR consideraba que los problemas de la agricultura en Colombia eran técnicos, relacionados con la mínima formación de profesionales en las ramas de la agricultura y con la escasez del empleo de tecnología agronómica. Esta situación conllevó a que se desarrollaran procesos tecnológicos, con fundamentos genéticos, químicos y agronómicos, como el mejoramiento de semillas de maíz con la pretensión de comenzar a reemplazar el cultivo de las razas tradicionales por semillas mejoradas, que prometían mayor producción en menos tierra, resistentes a plagas, enfermedades y adaptables según cada piso térmico del territorio antioqueño.

\title{
3. Producción de semillas en las Estaciones Agrícolas Experimentales
}

En la década de 1920 se rastrearon los primeros trabajos experimentales sobre el mejoramiento del cultivo de maíz en Antioquia. En la Estación Agronómica Departamental se "efectuaron ensayos preliminares sobre la siembra de maíz con abonos y según las épocas de siembra". ${ }^{54}$ Para esos años, el Ministerio de Industrias Nacional introdujo un lote de semillas mejoradas y seleccionadas en los Estados Unidos como la "Early sunshine", "Stowell evergreen", "Golden bantam" y "Early surprise" para "propagarlas en la granja de la Escuela de Agricultura Tropical de Medellín y repartirla a los agricultores" ${ }^{55}$ En 1a década de 1930 estas instituciones antioqueñas también experimentaron con semillas de "maíz pergamino colorado tipo

\footnotetext{
${ }^{51}$ Manuel Torregroza, "Variedades de híbridos de maíz para una alta productividad", Conferencias sobre el cultivo de maíz (Bucaramanga: ICA, 1976) 122.

${ }^{52}$ Fernando Suárez de Castro, “Agricultores y técnicos”, Boletín Agrícola 479 (1960): 7624-7626.

${ }^{53}$ Manuel Torregroza. "Maíz y Sorgo: dos cereales básicos de la agricultura colombiana” (Bogotá: ICA) 2-46. En línea: https://repository.agrosavia.co/handle/20.500.12324/12056 (02.02.2019).

54 "Informe sobre las labores efectuadas en la Estación Experimental Agronómica Departamental", Medellín, 25 de febrero de 1929. Archivo Histórico Universidad Nacional de Medellín (AHUNM), Fondo Escuela de Agricultura Tropical (FEAT), Caja 24, carpeta 3, ff. 61-63.

55 "Carta del Ministerio de Industrias al director de la Escuela de Agricultura Tropical", Bogotá, 23 de septiembre de 1929. AHUNM, FEAT, Caja 24, carpeta 3, f. 252.
} 
piamontés", "cuarentón colorado", "Long White Flint" y "canario de ocho filas", procedentes de Argentina, con el propósito de adaptarlas al territorio antioqueño y comenzar a experimentar con variedades extranjeras. ${ }^{56}$

Estos primeros esfuerzos, más que simples antecedentes del mejoramiento del cultivo y las semillas de maíz que tendría lugar en Antioquia a partir de la década de 1940 con el desarrollo del programa agrícola de la FR y el Ministerio de Agricultura, demuestran que en las escuelas y estaciones agrícolas de Medellín se realizaron trabajos de experimentación agronómica mucho antes de este despliegue institucional y científico de la Revolución Verde en Colombia. De esta manera se puede observar que la modernización agronómica en Antioquia tampoco nació con la FR y la Revolución Verde, como se ha señalado generalmente en la historiografía para otros lugares de latinoamericana, ${ }^{57}$ pues de manera previa se realizaron trabajos de investigación y experimentación que sirvieron como base para el programa de estas instituciones en Antioquia. Asimismo, en la década de 1920, el gobierno colombiano con la expedición de la Ley 74 sobre fomento de la agricultura estableció las bases de un programa de educación agrícola qué estimuló la creación de estaciones de experimentación y demostración agropecuaria. ${ }^{58}$ En este contexto, en Antioquia se fundaron una de las primeras estaciones y granjas experimentales del país. ${ }^{59}$

En Medellín, la Sociedad de Agricultores de Antioquia organizó una escuela y granja agrícola donde se realizaban algunos estudios agrícolas, relacionados especialmente con el cultivo de café. En torno a esta granja-escuela se formó la Escuela Superior de Agricultura de Medellín, la cual fue reformada en la década de 1920 por el agrónomo y experto puertorriqueño Carlos Chardón, dando origen a la Escuela de Agricultura Tropical y Veterinaria de Medellín, donde se formaron los primeros ingenieros agrónomos de Colombia. ${ }^{60}$ El objetivo de Chardón era realizar un proyecto de modernización agrícola en Antioquia y el Valle del Cauca basado en la experiencia de las estaciones experimentales y la formación agronómica del Caribe, que a su vez se sustentaba en la agricultura científica desplegada por los Estados Unidos. ${ }^{61}$ En medio de las reformas realizadas por Chardón en Colombia, sobresale la organización de estaciones experimentales, por ejemplo, la granja experimental de la Escuela de Agricultura, se transformó en la Estación Experimental de Clima Medio de Medellín; la cual en las décadas de 1940 y 1950 se convirtió en la Estación Tulio

\footnotetext{
56 "Carta del Ministerio de Industrias al director del Instituto Agrícola Nacional”, Bogotá, 26 de febrero de 1936. AHUNM, FEAT, Caja 31, carpeta 3, f. 59

${ }^{57}$ Picado 160.

${ }^{58}$ Ley 74 de 1926. Diario Oficial, Año LXII, No. 20361, 1.

${ }^{59}$ También se crearon las estaciones La Frontera en Caldas en 1929, la de Armero-Tolima en 1933, la del departamento del Atlántico en 1936 y la de Santander en 1946, además de otras veintiocho granjas agrícolas y ganaderas entre 1928 y 1943. Jesús Antonio Bejarano, "Las técnicas agropecuarias en el siglo XX", pp. 297-298.

${ }^{60}$ La Estación de Clima Medio estuvo anexa a la FNA de Medellín. Jairo Osorio Saraz et al., "Historia y presencia de la Facultad de Ciencias Agrarias de la Universidad Nacional de Colombia, sede Medellín, 1914-2017" (Texto inédito) 5.

${ }^{61}$ Stuart McCook 105-127.
} 
Ospina, donde la dirección del programa agrícola colombiano de la FR estableció su lugar de trabajo.

Así pues, en Medellín la experimentación agronómica comenzó antes de la llegada de la Revolución Verde. No obstante, la FR también organizó estaciones y granjas experimentales situadas estratégicamente en varias zonas climáticas de Antioquia. La estación de clima medio Tulio Ospina, situada primero en Medellín, y posteriormente en Bello, la granja experimental de clima frío La Selva en Rionegro y la estación de clima cálido Tulenapa en el Urabá (Figura 1). De especial interés para el cultivo de maíz fueron las investigaciones y labores realizadas en estas estaciones experimentales. En la estación Tulio Ospina se seleccionaron y mejoraron las primeras variedades de semillas de maíz con "características superiores" en cuanto a rendimiento, resistencia a plagas y enfermedades creadas para los agricultores del departamento de Antioquia.

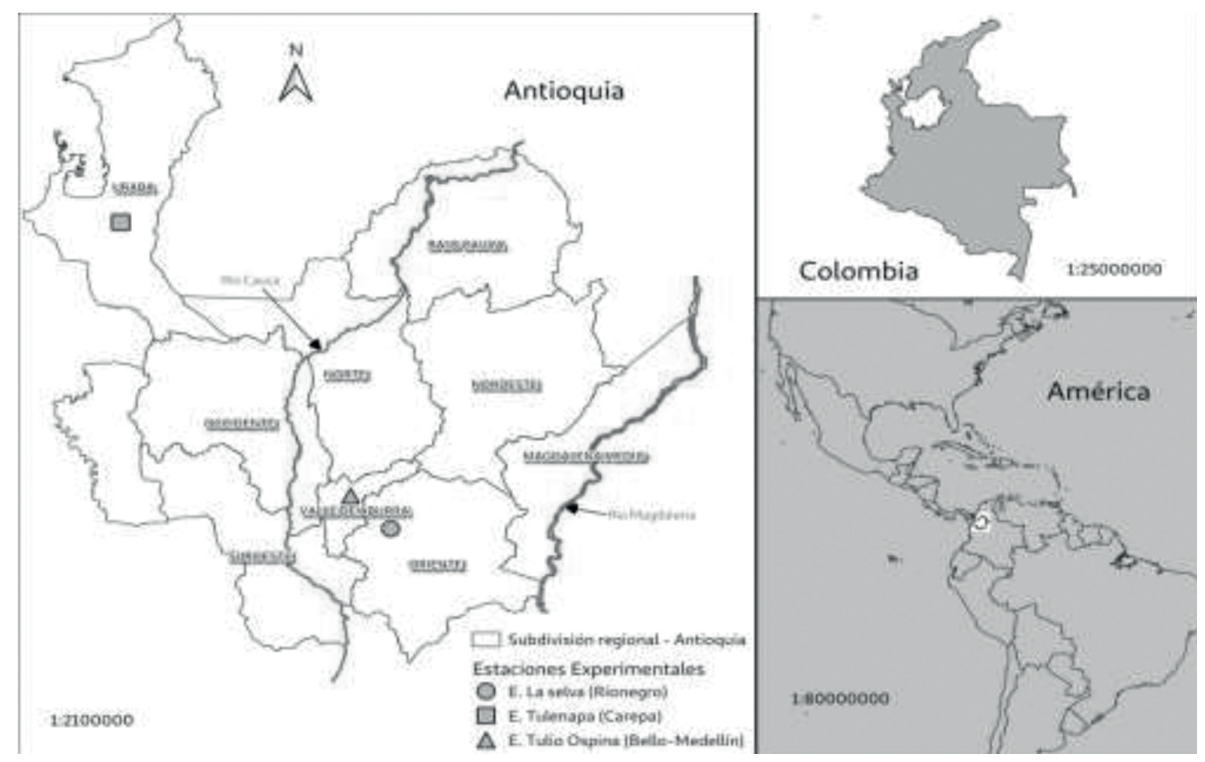

Figura 1: Estaciones de experimentación agrícola en Antioquia, 1950-1980

Fuente: Elaboración propia de los autores.

Una de las principales líneas de trabajo de estas instituciones era el fitomejoramiento de las semillas de maíz, tanto en genética como en agronomía. Los agrónomos trabajaron "en la creación y sostenimiento de líneas puras para la producción de híbridos; selección y producción de nuevas variedades de semillas de mayor rendimiento para atender las demandas de los consumidores y las industrias del maíz". ${ }^{62}$ En cuanto a cuestiones agronómicas realizaron estudios sobre la densidad de la siembra, aplicación de fertilizantes, el uso de cal agrícola y ensayos sobre fórmulas

${ }^{62}$ Emilio Yepes, "El maíz y su industrialización”, IX Conferencia del programa de maíz y sorgo, (Cereté, ICA, 1967) 87-88. 
de abonos químicos. ${ }^{63}$ Es importante señalar que el fitomejoramiento, entendido como el mejoramiento genético de las plantas, fue la principal técnica empleada en estas estaciones agrícolas. Las técnicas de fitomejoramiento en América Latina se basaron en la "genética hereditaria mendeliana" para crear plantas y granos uniformes que aumentaran la producción de maíz. ${ }^{64} \mathrm{El}$ método mendeliano tenía en cuenta el conjunto de caracteres genéticos para controlar y reproducir nuevas variedades con base en la herencia de las características deseadas de las plantas. De esta manera, en el caso del maíz, la genética agrícola mendeliana fue la principal técnica empleada en las estaciones experimentales para la creación de nuevas semillas.

En este sentido, los primeros trabajos dejaron como resultado cuatro variedades mejoradas de maíz: "Colombia 1 amarillo", "Colombia 2 blanco", "maíz dulce Medellín y la variedad ETO de maíz amarillo". ${ }^{65}$ Esta última variedad fue creada por el equipo de investigación del agrónomo Eduardo Chavarriaga Misas con base en razas criollas colombianas y también con material de maíces mejorados en los Estados Unidos y México, introducidos al país por el profesor E.W. Lindstrom, quien visitó la FNA de Medellín en 1945, en el marco de los acuerdos cooperativos entre el gobierno colombiano y la FR. ${ }^{66}$ Esta nueva variedad se convirtió en una importante fuente de germoplasma para la producción de nuevas variedades en el programa agrícola colombiano y centroamericano.

La década del cincuenta fue bastante productiva en el mejoramiento de semillas maíz en la estación Tulio Ospina. En 1952 los agrónomos de esta estación obtuvieron su primera semilla de maíz hibrida comercial, llamada ROCOL H201, maíz amarillo con un rendimiento promedio de $4.000 \mathrm{~kg} / \mathrm{ha}$. Este híbrido "superó a las anteriores semillas mejoradas y tuvo una magnifica aceptación entre los agricultores". ${ }^{67}$ En 1954 la estación produjo las semillas ROCOL H202 y ROCOL H203, ambas de color amarillo, granos finos y con un promedio de $4.000 \mathrm{~kg} / \mathrm{ha}$ de producción. ${ }^{6}$ En esta estación también mejoraron una variedad llamada "Maíz Dulce Medellín" usada para el consumo humano en "arepas de chócolo y comercializado en enlatados" ${ }^{69}$ En la estación Tulio Ospina entre 1946 y 1980 produjeron alrededor de diecinueve semillas mejoradas de maíz para cultivos comerciales de clima medio y con rendimientos superiores a $\operatorname{los} 3.000 \mathrm{~kg} / \mathrm{ha}$.

\footnotetext{
${ }^{63}$ Carlos Santamaría Sanz, Plan quinquenal de fomento agrícola 8-9.

${ }^{64}$ Netzahualcóyotl Gutiérrez Núñez, "Entre lo inesperado y lo imprevisto: la sequía y los proyectos de mejoramiento de maíz y sorgo en El Bajío, 1943-1970”, Historia Mexicana LXX, 1 (2020): 215-225.

${ }^{65}$ El maíz ETO recibe su nombre de la sigla Estación Tulio Ospina. Eduardo Chavarriaga Misas, "Maíz ETO, una variedad producida en Colombia", Revista ICA 1.1 (1966): 5-30.

${ }^{66}$ Eduardo Chavarriaga Misas, "Maíz ETO” 8-11.

${ }^{67}$ ROCOL significa Rockefeller-Colombia. Ministerio de Agricultura, "II Informe” 27-28.

${ }^{68}$ Ministerio de Agricultura, "IV Informe sobre el progreso del Programa Cooperativo entre el Ministerio de Agricultura y la Fundación Rockefeller”, Revista Nacional de Agricultura 614 (1956): 22.

${ }^{69}$ Fernando Arboleda, "Algunas características de maíces de alto valor nutritivo y de uso industrial”, Conferencias sobre el cultivo de maíz en Colombia (Bucaramanga: ICA, 1975) 149-151.
} 
Durante esos años se presentaron cambios institucionales que generaron un aparato oficial de apoyo a la agricultura. ${ }^{70} \mathrm{De}$ acuerdo con Wilson Picado, las actividades de la FR en Colombia tomaron un rumbo similar al programa mexicano, mostrando una especie de "clonación institucional" ${ }^{71}$ En 1950 fue establecida la Oficina de Investigaciones Especiales -OIE- entre el gobierno colombiano y la FR. La creación de esta oficina fue una "gran revolución en el cultivo de maíz", pues las primeras actividades fueron el mejoramiento de este producto mediante principios genéticos y métodos fito-técnicos. ${ }^{72}$ En 1955, fue creado el Departamento de Investigación Agropecuaria -DIA- como dependencia del Ministerio de Agricultura y la FR. En la década de 1950 las semillas producidas por esta entidad recibieron el nombre de DIACOL (Figura 2). Luego, en 1962 con base en las instituciones anteriores se creó el Instituto Colombiano Agropecuario (ICA).$^{73}$ Esa entidad se hizo cargo de la administración y funcionamiento de las estaciones experimentales, entre esas la estación de Bello, la cual comenzó a llamarse Centro Regional de Investigación Tulio Ospina. A partir de entonces, la investigación agrícola y el mejoramiento de maíz en Antioquia y otras regiones de Colombia, entró en una fase de intensa experimentación y producción de semillas mejoradas, las cuales tomaron la nomenclatura del nuevo instituto.

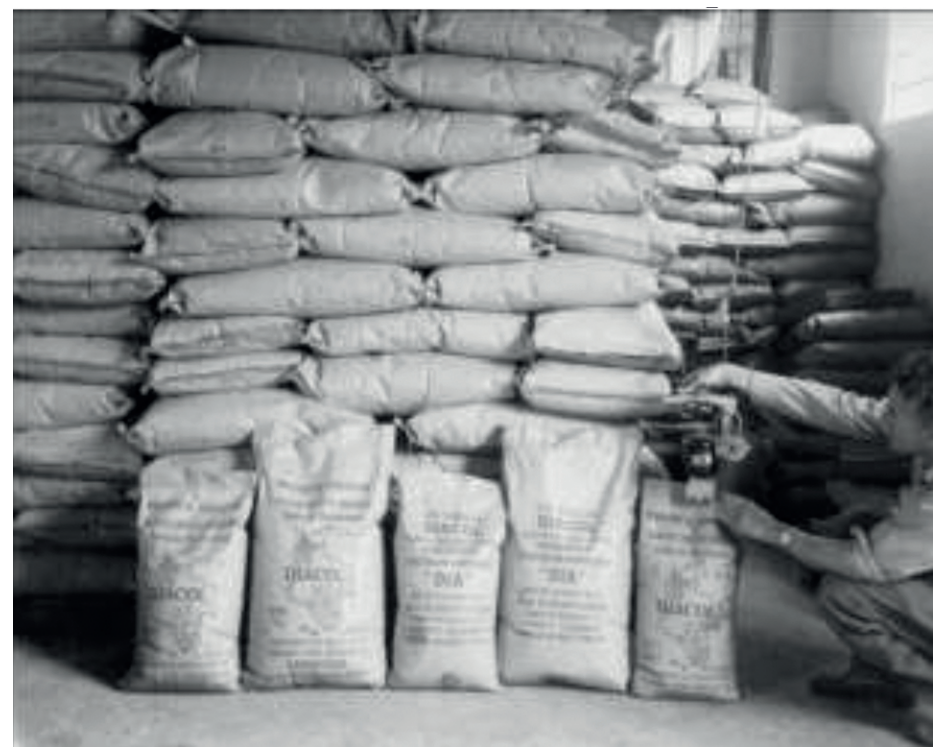

Figura 2. Semillas certificadas en la Estación Tulio Ospina, marca Diacol, 1950

Fuente: Registro Fotográfico Centro de Investigación Agrosavia La Selva, Rionegro, Antioquia.

\footnotetext{
${ }^{70}$ Arturo Warman, La Historia de un bastardo: maíz y capitalismo (México: Fondo de Cultura Económica, 1988) 204.

${ }^{71}$ Picado 180.

${ }^{72}$ Fernando Arboleda, "Historia de la investigación del maíz en Colombia", ASIAVA, Edición especial (1989) 59 .

${ }^{73}$ Astrid Martínez, Planes de desarrollo y política agraria en Colombia, 1940-1978 (Bogotá: Centro de Investigaciones para el Desarrollo, Universidad Nacional de Colombia, 1986) 90.
} 
Desde entonces, las denominaciones de estas variedades de maíz hibrido denotan el resultado del proceso de aplicación científica para su transformación en una semilla con otros estándares de mayor producción. Sus nuevos nombres, que son acrónimos de lugares de creación y sus promotores, acompañados de una numeración que registra la innovación, distan de aquellos nombres asociados a la asignación de procesos culturales y sociales que exponen el esfuerzo de diversas comunidades que por décadas domesticaron una variedad para garantizar su alimento. Tras este nuevo estilo de etiqueta hay un proceso de control técnico, y por supuesto, de su mercado. De esta manera, empezó la tarea de divulgación sobre la existencia de una semilla mejorada, pero que estaba atada a una forma diferente de acceso y cultivo que implicaba una nueva relación, no exenta de dudas, del agricultor con el novedoso producto.

En esta perspectiva, en 1967 en la Estación Tulio Ospina crearon la semilla ICA H302, maíz amarillo y fino recomendado para zonas cafeteras con rendimiento de 5.6 toneladas por año y con fecundidad de 160 días. ${ }^{74}$ Esta semilla fue usada como material básico en la Campaña de Multiplicación de Semillas de la Caja Agraria. ${ }^{75}$ El mejoramiento de maíz en el centro Tulio Ospina continuó por lo menos hasta la década de 1980. Durante esos años presentaron la variedad de maíz amarillo "ICA V303", un compuesto formado con maíces de Centro América y el Caribe, cruzado con la variedad mejorada ETO. Una de las características principales de esta nueva variedad era su uso como materia prima en procesos industriales de producción de alimentos concentrados, en los procesos de trillada esta variedad tenía buenos rendimientos, "pues de una carga de $100 \mathrm{~kg}$ de granos de "ICA V303" se obtienen 80 kilos de maíz trillado y 20 kilos de salvado"; 76 este último producto usado en la alimentación de cerdos y aves de corral. Asimismo, la semilla ICA H353 de color blanco, recomendada para zonas cálidas y medias, en el proceso de trillada el rendimiento fue de $78 \mathrm{~kg}$ de maíz trillado y $22 \mathrm{~kg}$ de salvado. ${ }^{77}$

En la estación experimental La Selva, ubicada en el municipio de Rionegro, también fue importante la tecnificación de los cultivos de clima frío moderado. En el oriente antioqueño, el maíz constituía uno de los principales cultivos y era sembrado sobre todo por pequeños agricultores. La mayor parte de la producción estaba "destinada al autoconsumo en la finca, en la alimentación de la familia o como fuente de alimento para especies pecuarias como cerdos, aves y bovinos". ${ }^{78}$ Los sistemas de cultivos más utilizados era "el maíz en relevo con frijol”, primero se sembraba el maíz y a los cinco meses después se cultivaba frijol de enredadera al lado de las plantas de

\footnotetext{
${ }^{74}$ Manuel Torregroza, "Variedades de híbridos de maíz para una alta productividad", 122-133.

${ }^{75}$ ICA, Memorias 1965-1966 (Bogotá: ICA, 2010) 70.

${ }^{76}$ Carlos Díaz et al., "ICA V 303: variedad mejorada prolífica de maíz”, Plegable de divulgación No. 164, septiembre de 1982.

77 Actualidades: Boletín informativo de la Regional 4 ICA Antioquia-Chocó, Medellín, 17 de septiembre de 1984, 1-2.

${ }^{78}$ José Hernando Arias, "Recomendaciones para el cultivo de maíz en el oriente antioqueño", Documento de trabajo ICA 14 (1984) 52-53.
} 
maíz para utilizar la caña como tutor. Este sistema se practicaba especialmente en los municipios de El Carmen de Viboral, Rionegro, Marinilla, El Santuario, San Vicente y Guarne.

La Selva comenzó sus actividades en 1958 como subestación experimental, donde se realizaban "replicas" de los experimentos agrícolas diseñados en la estación Tulio Ospina. Sin embargo, en 1962 bajo la administración del ICA se transformó en un centro de investigación regional, el cual funciona en la actualidad. La función principal de la investigación en La Selva era generar tecnología para lograr una mayor productividad agrícola en las zonas de clima frio moderado, en especial para los cultivos de maíz, frijol, papa y frutales del Oriente antioqueño y otras regiones con clima y altitud similares. ${ }^{79}$ La Selva manejaba un programa de maíz dedicado a la producción de variedades e híbridos varietales con mayores rendimientos que las semillas criollas de maíz montaña y maíz capio. En este centro de investigación también mejoraron y crearon nuevas variedades y semillas híbridas de maíz, las cuales guardaron una relación fundamental con el cultivo de frijol. ${ }^{80}$

En 1960 obtuvieron la primera variedad mejorada, la semilla ICA V402, la cual era "resultado de un "compuesto" de mazorcas de maíz criollo montaña procedente de fincas del oriente antioqueño". ${ }^{81}$ En 1968 en La Selva se creó y comercializó la semilla ICA H452, primer híbrido blanco para clima frío moderado. ${ }^{82}$ En 1977 fue creada la variedad sintética de maíz blanco ICA V453, producida por el Programa de Maíz y Sorgo del ICA, a partir de una mezcla de maíces de clima frío procedentes de otras regiones de Colombia y África. Entre las principales características agronómicas de esta variedad sobresalía el alto rendimiento de $6.300 \mathrm{~kg} / \mathrm{ha}$ y el grosor de sus cañas, "capaces de soportar el peso del frijol cuando se utilizaba en cultivos asociados con frijol. ${ }^{83}$

Entre 1960 y 1980 en la estación La Selva produjeron y comercializaron por lo menos siete nuevas semillas mejoradas de maíz adecuadas para cultivos de clima frío moderado con rendimientos superiores a los $4.000 \mathrm{~kg} / \mathrm{ha} .{ }^{84}$ En 1980 fue creada la semilla híbrida amarillo ICA H403, la cual tenía características forrajeras, ya que después de la recolección del maíz en "estado chócolo", "las plantas se podían utilizar como ensilaje para la alimentación de ganado vacuno y era excelente para el relevo con frijol voluble por la fortaleza de sus tallos". ${ }^{85}$ En 1985 la coordinación

\footnotetext{
${ }^{79}$ María Cecilia Agudelo et al., "La Selva: Centro regional de Investigación”, Actualidades 34 (1989): 1-6.

${ }^{80}$ José Tobón y Jorge Llano, Como cultivar maíz en Antioquia (Medellín: ICA, 1977).

${ }^{81}$ Carlos Díaz Amarís y Jesús Gómez, "ICA V 402: primera variedad mejorada de maíz montaña amarillo para zonas frías moderadas", Plegable de Divulgación ICA 153 (1980).

${ }^{82}$ Fernando Arboleda, "Historia de la investigación del maíz en Colombia" 146.

${ }^{83}$ Antonio Rivera y Carlos Díaz Amarís, "ICA V 453: variedad sintética de maíz para zonas frías moderadas", Plegable de Divulgación ICA 126 (1977).

${ }^{84}$ Base de datos elaborada con información de la Biblioteca Agropecuaria de Colombia.

${ }^{85}$ Fernando Arboleda et al., "ICA H 403: híbrido varietal amarillo para clima frío moderado", Plegable de Divulgación ICA 208 (1987).
} 
nacional del programa de maíz del ICA se trasladó al centro de investigación La Selva. Los agrónomos de este lugar estaban encargados de la investigación sobre el maíz adaptable desde los 1.500 hasta los $2.800 \mathrm{msnm}$. En estas altitudes superiores se encontraba el 95\% de la producción de maíz para el consumo humano en Antioquia. ${ }^{86}$

En la zona del Urabá, considerada en los últimos años como la despensa de Antioquia, por su vocación agrícola, especialmente en la producción de plátanos, también funcionó un centro de experimentación regional dedicado a la investigación agropecuaria. El centro Tulenapa fue adquirido por el ICA en 1969, sin embargo, sus actividades de investigación comenzaron en 1972 ante la necesidad de aprovechar el potencial agrícola y pecuario de la subregión costera de Antioquia mediante la difusión y aplicación de técnicas con bases científicas. Las instalaciones del centro aún están situadas en el municipio de Carepa, sobre la carretera al mar, que comunica a Medellín con el municipio de Turbo. ${ }^{87}$ En la década de 1980 el centro tenía una extensión de 306 hectáreas, situadas en zonas de bosque húmedo tropical y en tierras representativas de clima cálido. ${ }^{88}$

Las investigaciones realizadas en este centro, al igual que en la estación Tulio Ospina y La Selva, estaban enfocadas inicialmente en el cultivo y la producción de maíz. Desde 1980 comenzaron las experimentaciones con maíces mejorados en el Urabá antioqueño, ${ }^{89}$ como resultado de este proceso, el centro de investigación Tulenapa produjo la nueva semilla ICA V157, la cual "resultó más rendidora que la variedad criolla conocida como "maíz puya", semilla utilizada generalmente por los agricultores tradicionales". ${ }^{90} \mathrm{El}$ centro Tulenapa entregó a comercialización esta nueva semilla, la cual "era de excelente producción y calidad del grano para los cultivos de tierra caliente". ${ }^{91}$ La nueva variedad de maíz blanco era recomendada para los climas cálidos de Urabá, Córdoba y Chocó por su fácil adaptación. Según los funcionarios del ICA, el pequeño agricultor de las poblaciones de Urabá con sus prácticas de siembra, podía lograr ingresos superiores “con sólo cambiar la semilla puya por la ICA V157". ${ }^{2}$

El trabajo de tantos años de investigaciones en estas estaciones y centros experimentales dejó como resultado por lo menos 26 variedades mejoradas y semillas híbridas de maíz entre 1940 y 1980 (Tabla 2). En el panorama agrícola departamental

\footnotetext{
${ }^{86}$ Actualidades: Boletín informativo de la Regional 4 ICA Antioquia-Chocó, Medellín, 5 de marzo de 1985.

${ }^{87}$ En la actualidad, Tulenapa es una sede de investigación y reserva forestal propiedad de la Facultad de Ciencias Agrarias de la Universidad de Antioquia.

${ }^{88}$ Actualidades: Boletín informativo de la Regional 4 ICA Antioquia-Chocó, Medellín, 3 de julio de 1985, $1-8$.

89 "Informe anual de 1987 del Centro de Investigación Regional Tulenapa" (Medellín: ICA, 1987) 7, 40.

${ }_{90}^{90}$ Actualidades: Boletín informativo de la Regional 4 ICA Antioquia-Chocó, Medellín, 15 de agosto de 1987, No. 5, 13-16.

${ }^{91}$ ICA, Resumen de actividades del ICA y sus proyecciones en las zonas de Urabá y sur de Córdoba (Bogotá: ICA, 1983) 1-17.

${ }^{92}$ Carlos Díaz Amarís y Fernando Arboleda. "ICA V 157: variedad blanca de maíz para la región de Urabá", XII Reunión de maiceros de la zona Andina, Quito 29 de septiembre-3 de octubre de 1986, 110-123.
} 
y nacional, las estaciones y centros de hibridación de Medellín y Bello, Rionegro y Urabá, fueron de total importancia en la tecnificación de la agricultura antioqueña a lo largo del siglo XX. El mejoramiento de las semillas de maíz es una muestra de cómo la ciencia aplicada a este producto pretendió reemplazar las semillas tradicionales por otras que genéticamente garantizara mayor producción en menor superficie de tierra, plantas con menores días de maduración y con menos posibilidades de riesgos por enfermedades y plagas. La creación de nuevas semillas híbridas y variedades mejoradas en estos centros y estaciones experimentales originó el nacimiento de la industria de las semillas certificadas de maíz en el departamento de Antioquia. ${ }^{93}$

Tabla 2. Semillas híbridas y mejoradas en las estaciones antioqueñas, 1946-1987

\begin{tabular}{|c|c|c|c|c|}
\hline Ã̃̃ & NOMBRE & COLOR & $\begin{array}{c}\text { RENDIMIENTO } \\
\text { KG/HA }\end{array}$ & $\begin{array}{c}\text { ESTACIÓN } \\
\text { EXPERIMENTAL }\end{array}$ \\
\hline 1946 & Colombia 1 & Amarillo & 3.500 & Tulio Ospina \\
\hline 1946 & $\begin{array}{c}\text { Maíz Dulce } \\
\text { Medellín }\end{array}$ & Amarillo & & Tulio Ospina \\
\hline 1947 & Colombia 2 & Blanco & 4.450 & Tulio Ospina \\
\hline 1948 & Colombia 4 & Blanco & 4.700 & Tulio Ospina \\
\hline 1949 & Antioquia & Amarillo & 3.800 & Tulio Ospina \\
\hline 1950 & ETO & Amarillo & 4.450 & Tulio Ospina \\
\hline 1950 & ROCOL H 201 & Amarillo & 4.000 & Tulio Ospina \\
\hline 1954 & ROCOL H 202 & Amarillo & 4.000 & Tulio Ospina \\
\hline 1954 & ROCOL H 203 & Amarillo & 4.000 & Tulio Ospina \\
\hline 1955 & DIACOL H 201 & Amarillo & 5.200 & Tulio Ospina \\
\hline 1955 & DIACOL H 202 & Amarillo & 4.500 & Tulio Ospina \\
\hline 1956 & DIACOL H 203 & Amarillo & 4.700 & Tulio Ospina \\
\hline 1956 & DIACOL H 251 & Amarillo & 4.950 & Tulio Ospina \\
\hline 1957 & DIACOL H 301 & Amarillo & 5.500 & Tulio Ospina \\
\hline 1957 & DIACOL V 351 & Blanco & 5.150 & Tulio Ospina \\
\hline 1959 & DIACOL H 352 & Blanco & 6.050 & Tulio Ospina \\
\hline 1967 & ICA H 302 & Amarillo & 5.000 & Tulio Ospina \\
\hline 1980 & ICA V 303 & Amarillo & & Tulio Ospina \\
\hline 1984 & ICA H 353 & Amarillo & & Tulio Ospina \\
\hline 1950 & DIACOL H 451 & Blanco & 4.500 & La Selva \\
\hline 1950 & DIACOL H 452 & Blanco & 5.000 & La Selva \\
\hline 1960 & ICA V 402 & Amarillo & & La Selva \\
\hline 1968 & ICA H 452 & Blanco & & La Selva \\
\hline 1977 & ICA V 453 & Blanco & 6.300 & La Selva \\
\hline 1987 & ICA H 403 & Amarillo & 6.500 & La Selva \\
\hline 1987 & ICA V 157 & Blanco & 4.500 & Tulenapa \\
\hline
\end{tabular}

Fuente: Elaboración propia con información de la Biblioteca Agropecuaria de Colombia.

\footnotetext{
${ }^{93}$ Sociedad Antioqueña de Agricultores, "Entrevista a Eduardo Chavarriaga Misas", Boletín Agrícola 429 (1956): 5533-5535.
} 


\section{Industria y comercio de las semillas certificadas}

En 1953 la tarea de multiplicar y distribuir las nuevas semillas mejoradas en los centros de hibridación fue encomendada a la Caja de Crédito Agrario, cuyas funciones eran preservar la pureza de las nuevas variedades, distribuir material puro y original de cada nueva variedad y vigilar los cultivos de multiplicación de las semillas. ${ }^{94}$ El material básico producido en las estaciones era entregado a la Caja Agraria, esta entidad multiplicaba mediante contratos con agricultores, luego los lotes de semillas eran trasladados de los campos de siembra a las plantas de tratamiento de la Caja Agraria. Una vez limpiada, seleccionada, tratada y empacada, la semilla se vendía a los agricultores interesados. ${ }^{95}$ La oficina central de la Campaña de Multiplicación de Semillas de maíz y frijol estaba en Medellín, con seccionales en Palmira y Montería, a cargo de ingenieros agrónomos colombianos. ${ }^{96}$

El Ministerio de Agricultura mediante la expedición del Decreto 140 de 1965 estableció las bases legales y técnicas para llevar a cabo la reglamentación sobre la producción y certificación de semillas mejoradas. ${ }^{97}$ Esta labor fue encomendada a la Oficina de Certificación de Semillas del ICA, institución que se encargaba de garantizar la pureza genética, promover el uso de semillas certificadas y recomendar las semillas más adecuadas para cada zona, las épocas de siembra y la cantidad necesaria de semilla por hectárea. ${ }^{98}$ Este decreto también estableció que las empresas privadas tenían derecho a producir, multiplicar, procesar y vender semillas híbridas y variedades mejoradas. De esta manera, inició la producción industrial de semillas en Colombia. ${ }^{99}$ La producción de semillas mejoradas de maíz activó nuevas formas de organización y gestión empresarial que muestran cómo la producción de este tipo de semillas se convirtió en un negocio regulado por el Estado, pero en manos del sector empresarial. ${ }^{100}$

La empresa Procesadora Agrícola Colombiana -PROACOL- de Palmira, fue la pionera de esta industria en el sector privado. ${ }^{101}$ En 1970 esta empresa lanzó al mercado la semilla "Súper A Doble 6". Esta semilla era considerada como "la verdadera revolución verde en Colombia porque es el híbrido de mayor producción comprobada por hectárea, de amplia adaptación recomendada para la costa Atlántica,

\footnotetext{
${ }^{94}$ Memoria del Ministerio de Agricultura 1957-195881.

${ }^{95}$ Ministerio de Agricultura, "VII Informe sobre el progreso del Programa de cooperación entre el Ministerio de Agricultura y la Fundación Rockefeller”, Revista Nacional de Agricultura 646 (1959): 9.

${ }^{96}$ Manuel Torregroza, "Producción y distribución de híbridos y variedades seleccionadas de maíz” 416.

${ }^{97}$ Ricardo Ramírez, "Producción y distribución de semillas de maíz”, Agricultura Tropical 21.12 (1965): 853-858.

${ }^{98}$ ICA. Memorias 1966-1967 (Bogotá: ICA, 1968) 209.

99 Álvaro Castillo,Desarrollo de la industria de semillas y factores inductores del cambio tecnológico en la agricultura en Colombia, 1945-1993 (Bogotá: CEGA, 1995) 33

${ }^{100}$ Ricardo Ramírez. "Multiplicación, certificación y distribución de semillas de maíz”, IX Conferencia de del Programa de Maíz y Sorgo (Cereté: ICA, 1967) 77-83.

101 Iván Vera, "La Industria privada en la multiplicación y certificación de semillas mejoradas", $I X$ Conferencia de del Programa de Maíz y Sorgo, (Cereté: ICA, 1967) 83-85.
} 
Llanos Orientales, Magdalena Medio antioqueño y Valle del Cauca". ${ }^{102}$ Para finales del siglo XX existían en Colombia más de treinta empresas productoras de semillas mejoradas y certificadas, varias de ellas en Medellín y Antioquia. Entre las compañías registradas en el ICA y el Ministerio de Agricultura sobresalían Cresemillas, Semillas Valle, Germán Uribe y Empresa Agrícola de Occidente; ${ }^{103}$ Prosemillas, Semillas del Tolima Ltda., Proagro Ltda., Fenalce y Maizena S.A.; asimismo, estaba Colsemillas y Purina, empresas que se encargaban de multiplicar y distribuir en el país los materiales producidos por compañías internacionales como Northrup King, Asgrow y Pionner. ${ }^{104}$

Como se puede notar, la experimentación y producción de semillas mejoradas dio paso al uso de estas como una nueva mercancía tecnológica. En este proceso de certificación de semillas se estableció un vínculo entre las estaciones experimentales, la FR, las empresas privadas y las políticas del gobierno colombiano en torno a variedades estandarizadas de semillas certificadas con potencial comercial. De esta manera se puede demostrar una vez más que el programa científico de renovación agrícola de la FR y la Revolución Verde no tenía solo fines filantrópicos, pues también tenía intereses comerciales con la producción y venta de semillas certificadas.

Es importante señalar que hasta la década de 1950 la mayoría de las semillas mejoradas de maíz utilizadas en el país eran importadas de los Estados Unidos y México principalmente. Sin embargo, la semilla proveniente de los materiales obtenidos por la investigación nacional disminuyeron las importaciones de semillas mejoradas, pues hacia 1976 existían en el mercado 89 híbridos y variedades obtenidas en las estaciones experimentales del ICA y por productores particulares. ${ }^{105}$ En la década de 1980 la producción nacional de semillas tuvo incrementó, pues el país comenzó a autoabastecerse de estas semillas y estaba en la capacidad de producir excedentes exportables. ${ }^{106}$ De acuerdo con datos suministrados por la Campaña de Multiplicación de Semillas de Maíz de la Caja de Crédito Agrario, las cantidades distribuidas desde 1953 hasta 1965 fueron de 8.847.875 kilogramos correspondientes para un área aproximada de 520.440 hectáreas. ${ }^{107}$

En 1967 en la estación Tulio Ospina produjeron 14 toneladas de semillas DIACOL H401 y DIACOL H452 para sembrar un área de 932 hectáreas. ${ }^{108}$ La cantidad de semilla vendida de estos dos híbridos para las siembras de 1968 representó en Antioquia el $50 \%$ de lo que este departamento usó como semilla mejorada para otros

\footnotetext{
102 "Aviso publicitario de Proacol”, Agro Sintesis 326 (1974).

${ }^{103}$ Antonio Rivera Gómez y Jorge Enrique Llano, "Pruebas regionales de maíz en Colombia", Boletín de Divulgación 13 (Medellín: ICA, 1974) 22-40.

${ }^{104}$ Manuel Torregroza, "Maíz y Sorgo" 4-46.

105 “38 productores de semillas en el país”, Agro Síntesis 496 (1977) 13-15.

${ }^{106}$ Alejandro Mendoza Osorio, "Situación de la producción de semillas en Colombia", Memorias Foro Tecnológico sobre producción de semillas (Medellín, ICA, 1989) 9-23.

${ }^{107}$ ICA. Memorias 1965-1966, 72.

${ }^{108}$ Ricardo Ramírez. "Multiplicación, certificación y distribución de semillas de maíz”, 79.
} 
climas distintos al frío moderado. ${ }^{109}$ Entre 1975 y 1986 en Colombia se sembraron 7.384 hectáreas con maíces mejorados en las estaciones experimentales, correspondientes a 26.033 toneladas de semillas. ${ }^{110}$ No obstante, a pesar del crecimiento de la industria de la producción de semillas de maíz, el uso de las nuevas variedades certificadas no aumentó proporcionalmente y tampoco su utilización estuvo difundida y generalizada entre los agricultores antioqueños y colombianos.

\section{Los agricultores y el uso de las semillas certificadas}

En 1955 el agrónomo José Guerra señalaba que “a pesar de que ya tenemos híbridos y variedades producidas por la oficina de investigaciones especiales del Ministerio de Agricultura y la FR, el cultivo de maíz en Colombia, con excepciones de algunos lugares, es altamente empírico y antieconómico". ${ }^{111}$ Los mismos agrónomos observaban que "el esfuerzo que está haciendo el ICA en producir materiales de buena calidad se está quedando prácticamente a nivel de centro de investigación"; 112 pues entre las décadas de 1950 y 1980 la tendencia en el uso de la semilla certificada demostró una disminución en Antioquia y el país en general. ${ }^{113}$ De los sectores maiceros, el tradicional usaba muy poca semilla mejorada debido a factores como los costos de producción, los cuales además de la compra de la semilla, incluía gastos de fertilización y adopción de la tecnología recomendada por los agrónomos en el llamado "paquete tecnológico", que incluía semillas mejoradas, instrucciones sobre el tiempo de siembra, la distancia entre plantas y surcos, el número de semillas por sitio y la cantidad recomendada de fertilizantes; además del estudio previo de suelos y el empleo de maquinaria agrícola y sistema de riego.

Según el agrónomo Manuel Torregroza, uno de los problemas que afrontaba la agricultura maicera del sector tradicional era conseguir semillas certificadas, en especial de los híbridos varietales. Los productores de semilla de maíz, sobre todo los del sector privado, "no han dado importancia a la multiplicación y distribución de algunos maíces mejorados". ${ }^{114}$ En esta misma perspectiva, el mejorador de maíz Fernando Arboleda, apuntaba que el sector tradicional era "castigado tanto por la empresa privada como por la oficial en el suministro del principal de los insumos: las semillas mejoradas", pues "el $95 \%$ de las semillas producidas por el ICA y las empresas privadas se destinaba para la agricultura mecanizada". ${ }^{115}$ Esta era una de las razones principales del bajo uso de semillas certificada entre los agricultores tradicionales del departamento de Antioquia.

\footnotetext{
${ }^{109}$ ICA. Memorias 1966-1967 88-89.

${ }^{110}$ Carlos Díaz Amarís, "Utilización de la semilla mejorada de maíz en Colombia", (ICA: Biblioteca Agropecuaria de Colombia, 1986) 24-30.

${ }^{111}$ José Guerra, “Campaña para aumentar la producción de maíz”, Boletín Agrícola 419 (1955): 5073.

${ }^{112}$ Actualidades: Boletín informativo de la Regional 4 ICA Antioquia-Chocó, Medellín, 15 de junio de 1987, 2-12.

${ }^{113}$ Carlos Díaz Amarís, "Utilización de la semilla mejorada de maíz” 24-30.

${ }^{114}$ Manuel Torregroza, "Variedades de híbridos de maíz para una alta productividad” 128.

115 Fernando Arboleda Rivera, "Programa nacional de maíz del ICA 1962-1987: problemáticas y realizaciones”, Actualidades 12 (1987) 2-5.
} 
En el sistema de producción y distribución de semillas certificadas de la Caja Agraria el agricultor "tenía que pagar la semilla mejorada a un valor considerablemente más alto que la semilla criolla". ${ }^{116}$ En 1984 un kilogramo de semillas de maíz de las variedades ICA V402 e ICA V453 costaba \$70.00 en el almacén de la estación La Selva. Sin embargo, es importante señalar que el precio de las semillas de maíz en el costo de la producción por hectárea era menor en comparación con los gastos de labores de preparación del terreno, siembra y cosecha y con relación a otros insumos como los fertilizantes; necesarios para la germinación y producción de las nuevas semillas. ${ }^{117}$ De otro lado, los cultivadores de maíz tampoco tenían subsidio oficial que entregara "una semilla buena y barata". En este sentido, los campesinos del municipio El Santuario, en el oriente antioqueño, manifestaron a las autoridades agrícolas la necesidad de "establecer un programa para la producción de semillas para el agricultor de bajos recursos". ${ }^{118}$

Algunos analistas señalaban que el descenso de la producción de maíz en Antioquia se "debió a la falta de semillas mejoradas, las cuales no llegaban al productor en la época oportuna ni en los volúmenes requeridos". ${ }^{119}$ Esto también se convirtió en un factor que desestimuló la utilización de semillas certificadas entre los agricultores antioqueños. Según los investigadores colombianos, el porcentaje de utilización de semilla mejorada no sobrepasaba el $18 \%$, que, junto a la poca aplicación de la tecnología agronómica recomendada en el paquete tecnológico, eran los dos factores causantes de la baja productividad de la agricultura maicera tradicional. ${ }^{120}$ En la zona andina antioqueña, importante región maicera, "la utilización de semillas mejoradas era baja; se usaban semillas de maíces no mejorados y de pobres características agronómicas". ${ }^{121}$

En un diagnóstico realizado por el ICA sobre el uso de semillas en Sonsón, El Carmen de Viboral, San Vicente y Marinilla en el Oriente antioqueño demostró que la mayoría de los agricultores seleccionaban su propia semilla de maíces criollos, a pesar de la gran cantidad de semillas híbridas y mejoradas que circulaban en el mercado. El uso de semillas certificadas no era generalizado, solo un minúsculo grupo de agricultores usaba semillas certificadas de maíz distribuido por la Caja Agraria. En El Carmen de Viboral el 47\% de los agricultores de maíz emplearon semillas seleccionadas en sus propias fincas, el $26 \%$ utilizaba semilla certificada y otro $17 \%$ obtenía la semilla mediante el intercambio con otros productores, lo cual constituía una práctica cultural de los campesinos y pequeños productores de la región. Las

\footnotetext{
${ }^{116}$ Nelson Estrada Ramos, "Las variedades mejoradas, la selección de semillas y el fomento agrícola", Agricultura Tropical 16.10 (1960) 629.

${ }^{117}$ Secretaría de Agricultura de Antioquia, Costos de producción por hectárea, 1979, 1982, 1984 (Medellín: Gobernación de Antioquia).

${ }^{118}$ Actualidades: Boletín informativo de la Regional 4 ICA Antioquia-Chocó, Medellín, 15 de junio de 1983, 1.

${ }^{119}$ Antioquia Agropecuaria, primer semestre de 1989, 21.

${ }^{120}$ Secretaría de Agricultura de Antioquia, Consideraciones y propuestas sobre el cultivo de maiz en Antioquia, Tomo I (Medellín: Gobernación de Antioquia, 1983) 15.

${ }^{121}$ Manuel Torregroza, "Maíz y Sorgo” 4-30.
} 
semillas empleadas por los agricultores continuaron siendo las variedades capio y montaña, principalmente. ${ }^{122}$

Los agricultores de maíz del Oriente antioqueño tenían más facilidad para hacer sus selecciones con base en aspectos físicos de los lotes, plantas, mazorcas y granos de sus propias cosechas; tenían mayor confianza en sus propias semillas adaptadas a las condiciones de sus explotaciones. ${ }^{123}$ Asimismo, los resultados de varios cultivos experimentales demostraron que "no parece viable ni recomendable el cambio de las variedades criollas". En algunas pruebas el maíz ICA V453 "era muy achaparrado, con mazorcas bajas y pequeñas, un alto porcentaje de plantas sin mazorcas, mientras que el maíz criollo montaña mostró mejores mazorcas, mejor porte y resistencia de la caña; en general, este lote estaba en mejor situación que el V453". ${ }^{124}$ De igual forma sucedió con la semilla híbrida ICA H401, cuyas plantas se "volcaban fácilmente y sufría competencia con la papa". ${ }^{125}$ Estos resultados también fueron factores que limitaron el uso de semillas híbridas y las variedades mejoradas entre los agricultores antioqueños.

En otras latitudes y regiones de Antioquia también se mantuvo la tendencia del bajo uso de semillas mejoradas y certificadas. En el Bajo Cauca se "cultivaba principalmente maíz criollo de color blanco, la gente casi no conoce los maíces mejorados ni el incremento que se obtiene con ellos". ${ }^{126}$ En las zonas de colonización como el Urabá antioqueño "la costumbre era sembrar maíz para luego pasar a sembrar pastos y construir potreros, este proceder era uno de causantes de que no se haya desarrollado la tecnología del cultivo". ${ }^{127}$ Los agricultores que sembraban para el autoconsumo y como antesala para el cultivo de pastos en zonas ganaderas como el Magdalena Medio "no usaban semillas mejoradas ni abonos"128. A esto se debe sumar la ineficacia de los programas de transferencia de tecnologías y extensión agrícola implementados por las instituciones del gobierno.

Un factor central en el bajo uso de semillas mejoradas fue el distanciamiento entre agrónomos y agricultores que no establecieron diálogos ni prácticas productivas a favor del cultivo de maíz. Los agrónomos consideraban que los agricultores y sus sistemas de cultivos eran atrasados. Según los agrónomos, los agricultores "despreciaban la ayuda de los profesionales que en todas las latitudes han sido el más firme soporte del progreso rural". Mientras tanto, según los agricultores, los agrónomos "se encierran en su torre del marfil y se distancian del grupo que

\footnotetext{
${ }^{122}$ Jesús Arias Restrepo y Héctor Lopera, "Diagnóstico de la producción y usos de semilla de papa, maíz y frijol en el Oriente antioqueño”, Boletín de investigación 75 (1988) 27-30.

${ }^{123}$ Jesús Arias Restrepo y Héctor Lopera, 31.

${ }^{124}$ José Tobón y Jorge Llano, Análisis de los resultados de ensayos en fincas con maíz ICA V 453 y criollo en el Oriente antioqueño (Rionegro: ICA, 1981) 12.

${ }^{125}$ José Tobón y Jorge Llano, “Como cultivar maíz en Antioquia”, Cartilla Ilustrada ICA 17, 11.

${ }^{126}$ Guillermo Guerra et al., "Maíz y millo en Colombia”, p. 75.

${ }^{127}$ Secretaría de Agricultura de Antioquia, Consideraciones y propuestas 56-58.

${ }^{128}$ Guillermo Guerra, "Maíz y millo en Colombia”, 25.
} 
mejor podría aprovechar sus conocimientos". ${ }^{129}$ Esta era una situación de reciproca controversia, pues "no siempre los agricultores han querido comprender la misión de los ingenieros agrónomos y no siempre los agrónomos han sabido llegar hasta los agricultores". ${ }^{130}$ Según algunos críticos de la agronomía, "planear cultivos desde una oficina era cosa sencilla, pero la práctica muestra las dificultades del suelo, clima, falta de agua o excesiva humedad, todo lo cual hace que los programas agrícolas institucionales fracasen". ${ }^{131}$

En esta relación agrónomos-agricultores, los técnicos y científicos tomaron una posición paternalista que victimizaba y menospreciaba el trabajo y saberes del agricultor; pero al mismo tiempo, legitimaba la intervención, el trabajo y conocimiento del agrónomo. Mientras que los agricultores, por su parte, tomaron una posición reacia y escéptica en vista de la relación de poder que imponía la legitimidad científica del agrónomo. ${ }^{132} \mathrm{Al}$ respecto de este diálogo de sordos entre el saber científico y tradicional, se refleja el trabajo desvinculado entre academia y campesinos para complementar y validar las innovaciones; igualmente devela limitaciones tanto en las estrategias pedagógicas para la difusión de esos nuevos conocimientos, la indiferencia frente a hechos culturales asociados al gusto por el consumo las variedades criollas, así como también en la estrategias de financiación para la transición a proyectos productivos soportados en nuevas variedades del grano que requerían de otros insumos. Asimismo, la visión de los agrónomos se concentró más en el incremento de los rendimientos y productividad, asunto que se ajustaba más con el discurso de las elites agroindustriales que con las necesidades de los pequeños agricultores tradicionales.

Es importante señalar que las semillas certificadas estaban al servicio de la agricultura comercial, de la productividad industrial y en manos de grandes cultivadores, es decir, la agricultura tecnificada. ${ }^{133}$ En especial las semillas híbridas porque las variedades mejoradas eran "apropiadas para utilizar en agricultura de laderas o en regiones donde los agricultores han mostrado cierta oposición a cambiar la forma tradicional de sembrar maíz". ${ }^{134}$ Las semillas híbridas para obtener altos rendimientos en monocultivos o asociados requerían de una tecnología agronómica sofisticada, terrenos planos y fértiles con disponibilidad de agua, tanto así que las nuevas variedades mal manejadas producían menos que las semillas criollas. Las nuevas semillas fueron empleadas por agricultores del Valle del Cauca y los valles del Sinú y San Jorge en el departamento de Córdoba; regiones de llanuras y clima cálido, donde se podía obtener dos cosechas por año. En estas regiones, los agroindustriales "tenían marcada preferencia por los materiales híbridos ICA H207, seguido por el DIACOL H253 y el Súper A doble 6". ${ }^{135}$

\footnotetext{
${ }^{129}$ Fernando Suárez de Castro, “Agricultores y técnicos” 7624-7626.

${ }^{130}$ Armando Samper, "Por una conciencia agraria”, Agricultura Tropical 7 (1946): 3-6.

${ }^{131}$ Secretaría de Agricultura de Antioquia, Informe de labores 1957-1958 (Medellín: Gobernación de Antioquia, 1958) 10.

132 Picado 241-245.

${ }^{133}$ Lina Salgar, "El cultivo de maíz en Colombia", Revista Semillas 22-23 (2004) 2-7. En línea: http://www. semillas.org.co/es/el-cultivo-de-maz-en-colombia (30.05.2019).

${ }^{134}$ Manuel Torregroza, "Variedades de híbridos de maíz para una alta productividad" 126.

${ }^{135}$ Secretaría de Agricultura de Antioquia, Consideraciones y propuestas 24-26.
} 
Así pues, esta serie de factores demuestran que las semillas mejoradas y certificadas por las instituciones de la Revolución Verde no tuvieron un uso generalizado y menos un impacto total en la producción de granos de maíz, por lo menos en el departamento de Antioquia, donde de manera simultánea al crecimiento de la industria de semillas, también creció su dependencia de granos importados de otras regiones de Colombia. ${ }^{136}$ Esto conduce a plantear dos asuntos: el primero, que el impacto de esta modernización agrícola no estuvo en la transformación de la estructura agraria ni en el aumento real de la producción de maíz, sino en la investigación, producción de tecnologías y la formación agronómica de un sector de la sociedad antioqueña. En Colombia y Antioquia en particular, a pesar de la generación y experimentación con las semillas certificadas, "la mayor parte de la producción provenía de razas colombianas cultivadas por pequeños agricultores". ${ }^{137} \mathrm{El}$ segundo, que las semillas criollas, en medio del tránsito hacia el uso de las semillas certificadas, continuaron ocupando un lugar primario entre los agricultores maiceros y también entre los agrónomos, como fuentes de material genético para el mejoramiento de las semillas de la Revolución Verde.

\section{Conclusiones}

En el marco de los programas agrícolas de la FR en Colombia y América Latina, los agrónomos, facultades, escuelas y estaciones experimentales del departamento de Antioquia ocuparon un importante lugar, no solo como un nodo de intercambios de conocimientos y experiencias, sino como un centro de producción de nuevas tecnologías agrícolas como las semillas certificadas de maíz. Entre los logros de este proceso de modernización se encuentra la generación de semillas híbridas y variedades mejoradas, diseñadas para aprovechar las diferentes características geográficas y climáticas del territorio antioqueño. Este intento de tecnificación del cultivo de maíz tenía como objetivo principal aumentar la producción del cereal, mediante la creación y aplicación de las nuevas semillas que prometieron mayores rendimientos que las variedades de raza criolla. Sin embargo, este proceso de tecnificación de las semillas y el cultivo de maíz no garantizaron el incremento de la producción del cereal en Antioquia.

Esta situación nos conduce a plantear la hipótesis de que, en este departamento, sobre todo en Medellín, la amplia producción de semillas hibridas y mejoradas no estuvo acompasada con el incremento de la producción y los rendimientos de las cosechas de maíz. Es decir, que la investigación agronómica se vinculó poco con la producción de este alimento y materia prima industrial. En este sentido, es válido plantear que el proceso de modernización agronómica iniciado desde la década de 1920, y consolidado entre las décadas de 1940 y 1980 con la intervención de la FR en Antioquia no se reflejó en el incremento de la producción de maíz, sino en la producción de semillas mejoradas e híbridas, las cuales fueron promocionadas como la superación de la improductividad de la agricultura antioqueña. Asimismo, en medio

\footnotetext{
${ }^{136}$ José Roberto Álvarez y Francisco Sibaja Madera, "De la autonomía a la dependencia. Maíz, mercado y alimentación en Antioquia en la primera mitad del siglo XX". Documento de trabajo inédito.

${ }^{137}$ Guillermo Guerra, "Maíz y millo en Colombia” 23-24.
} 
del tránsito hacia el uso de las semillas certificadas, la mayoría de cultivadores de maíz continuaron empleando las semillas criollas, las cuales no fueron reemplazadas totalmente. Los agricultores tenían sus propias semillas, conocían sus plantas, su tecnología o prácticas culturales de cultivo; eran conscientes de sus lógicas, conocimientos y recursos, por lo tanto, poco dispusieron de las nuevas tecnologías agronómicas y conservaron el uso de variedades criollas.

\section{Bibliografía}

\section{Fuentes primarias}

\section{Archivos}

Archivo Histórico Universidad Nacional de Medellín, Medellín-Colombia (AHUNM). Fondo Escuela de Agricultura Tropical (FEAT) y Fondo Decanatura.

Centro de Investigación Agrícola La Selva-Agrosavia, Rionegro-Antioquia. Registro Fotográfico.

\section{Bibliotecas}

Biblioteca Agropecuaria de Colombia (BAC), Mosquera-Cundinamarca. Documentos impresos y manuscritos.

Biblioteca Universidad de Antioquia, Medellín. Sala patrimonial. Documentos impresos y manuscritos, publicaciones periódicas.

Centro Cultural Biblioteca Luis Echavarría Villegas Universidad EAFIT, Medellín. Sala patrimonial. Documentos impresos y manuscritos, publicaciones periódicas.

\section{Documentos impresos e informes primarios}

Arboleda, Fernando et al., "ICA H 403: híbrido varietal amarillo para clima frío moderado", Plegable de Divulgación ICA 208 (1987).

Díaz Amarís, Carlos y Rivera, Antonio, "ICA V 453: variedad sintética de maíz para zonas frías moderadas", Plegable de Divulgación ICA 126 (1977).

Díaz Amarís, Carlos y Jesús Gómez, “ICA V 402: primera variedad mejorada de maíz montaña amarillo para zonas frías moderadas", Plegable de Divulgación ICA 153 (1980).

Díaz Amarís, Carlos et al., "ICA V 303: variedad mejorada prolífica de maíz", Plegable de divulgación No. 164, septiembre de 1982.

Díaz Amarís, Carlos “Utilización de la semilla mejorada de maíz en Colombia”, (ICA: Biblioteca Agropecuaria de Colombia, 1986) 24-30. 
Guerra, José,“Campaña para aumentar la producción de maíz”, Boletín Agrícola 419 (1955): 5073.

Santamaría Sanz, Carlos, Plan quinquenal de fomento agrícola en Colombia, 1945 (Bogotá: Ministerio de Economía Nacional, 1945).

Secretaría de Agricultura de Antioquia, Costos de producción por hectárea, 1979, 1982, 1984 (Medellín: Gobernación de Antioquia).

Secretaría de Agricultura de Antioquia, Informe de labores 1957-1958 (Medellín: Gobernación de Antioquia, 1958).

Secretaría de Agricultura de Antioquia, Consideraciones y propuestas sobre el cultivo de maiz en Antioquia, Tomo I (Medellín: Gobernación de Antioquia, 1983).

Sociedad Antioqueña de Agricultores, Segunda Asamblea Agraria de Antioquia y Exposición Agropecuaria y de Maquinaria Agrícola (Medellín: Imprenta Oficial, 1926) $1,25$.

Sociedad Antioqueña de Agricultores. "Entrevista a Eduardo Chavarriaga Misas". Boletín Agrícola 429 (1956): 5533-5535.

Memorias del Ministerio de Agricultura al Congreso Nacional, 1957-1958 (Bogotá: Imprenta Nacional, 1958) 78.

Ministerio de Agricultura, "I Informe sobre el progreso del Programa Cooperativo entre el Ministerio de Agricultura y la Fundación Rockefeller", Revista Nacional de Agricultura 554 (1951).

Ministerio de Agricultura, "II Informe sobre el progreso del Programa Cooperativo entre el Ministerio de Agricultura y la Fundación Rockefeller", Revista Nacional de Agricultura 585 (1952): 34-35.

Ministerio de Agricultura, "III Informe sobre el progreso del Programa Cooperativo entre el Ministerio de Agricultura y la Fundación Rockefeller", Revista Nacional de Agricultura 587 (1954).

Ministerio de Agricultura, "IV Informe sobre el progreso del Programa Cooperativo entre el Ministerio de Agricultura y la Fundación Rockefeller”, Revista Nacional de Agricultura 614 (1956).

Ministerio de Agricultura, "VII Informe sobre el progreso del Programa de cooperación entre el Ministerio de Agricultura y la Fundación Rockefeller", Revista Nacional de Agricultura 646 (1959). 
Tobón, José y Jorge Llano, “Como cultivar maíz en Antioquia”, Cartilla Ilustrada ICA $17,11$.

Uribe, Joaquín Antonio, "Climatología”, Anales de la Academia de Medicina de Medellín 9-11 (1907) 161-164.

\section{Prensa}

UN Periódico 84 (Medellín) 2005.

\section{Fuentes secundarias}

\section{Libros}

Castillo, Álvaro. Desarrollo de la industria de semillas y factores inductores del cambio tecnológico en la agricultura en Colombia, 1945-1993, Bogotá: CEGA, 1995.

Escobar, Arturo. La invención del tercer mundo. Construcción y deconstrucción del desarrollo, Caracas: Fundación Editorial El Perro y la Rana, 2007.

Fernández-Armesto, Felipe. Historia de la comida: alimentos, cocina y civilización, Barcelona: Tusquets Editores, 2009.

Gutiérrez González, Gregorio. Canto al Maíz, Medellín: Colegio Académico de Antioquia, 1956.

Henderson, James. La modernización en Colombia. Los años de Laureano Gómez, 1889-1965, Medellín: Editorial Universidad de Antioquia, 2006.

ICA. Memorias 1966-1967. Bogotá: ICA, 1968.

ICA. Memorias 1965-1966. Bogotá: ICA, 2010.

Jugenheimer, Robert. Maíz: variedades mejoradas, métodos de cultivo y producción de semillas, México: Limusa, 1988.

Martínez, Astrid. Planes de desarrollo y política agraria en Colombia, 1940-1978, Bogotá: Centro de Investigaciones para el Desarrollo, Universidad Nacional de Colombia, 1986.

Mesa Bernal, Daniel. Historia natural del maíz, Bogotá: Litografía de Colombia, 1957.

Patiño, Víctor Manuel. Plantas cultivadas y animales domésticos en América Equinoccial-Tomo II-, Cali: Imprenta Departamental, 1964. 
Roberts, L.M, et al., Razas de maiz en Colombia, Bogotá: Editorial Máxima, 1957.

Rodríguez, Jorge. Maízopolis: monografías de los distritos antioqueños, Medellín: Correo Liberal, 1915.

Saavedra, María et al. Facultad de Ciencias Agropecuarias: 90 años sembrando futuro, 1914-2004, Medellín: Universidad Nacional de Colombia, 2004.

Tobón, José y Jorge Llano. Análisis de los resultados de ensayos en fincas con maíz ICA V 453 y criollo en el Oriente antioqueño. Rionegro: ICA, 1981.

Warman, Arturo. La Historia de un bastardo: maíz y capitalismo, México: Fondo de Cultura Económica, 1988.

\section{Capítulos de libros}

Bejarano, Jesús Antonio. "Las técnicas agropecuarias en el siglo XX", Nueva Historia de Colombia, Bogotá: Planeta, 1989.

Cotter, Josep. "The Rockefeller Foundation's Mexican agricultural project. A cross-cultural encounter, 1943-1949", Missionaries of science: the Rockefeller Foundation and Latin America, ed. Marcos Cueto, Bloomington: Indiana Univerity Press, 1994, 97-125.

\section{Artículos de revistas}

Agudelo, María Cecilia et al., "La Selva: Centro regional de Investigación". Actualidades 34 (1989): 1-6.

Arango Marín, Mario. "La revista Facultad Nacional de Agronomía de Medellín como indicador del fraccionamiento especializado del saber agronómico". Revista Facultad Nacional de Agronomía 58. 2 (2005): 2801-2811.

Arboleda, Fernando. "Programa nacional de maíz del ICA 1962-1987: problemáticas y realizaciones". Actualidades 12 (1987) 2-5.

Arboleda, Fernando. "Historia de la investigación del maíz en Colombia". ASIAVA, Edición especial (1989) 59-70.

Cerutti, Mario. "Trigo y revolución verde en el noroeste de México, 1930-1970". Mundo Agrario 20. 43 (2019): 1-21.

Curry, Helen. "From working collections to the World Germplasm Project: agricultural modernization and genetic conservation al the Rockefeller Foundation", History and Philosophy of the Life Sciences, 39.5 (2017), pp. 1-20 
Chavarriaga Misas, Eduardo. "Variedades mejoradas de maíz". Revista Agricultura Tropical 3 (1948): 7-10.

Chavarriaga Misas, Eduardo. "Maíz ETO, una variedad producida en Colombia”. Revista ICA 1.1 (1996): 5-30.

Estrada Ramos, Nelson. "Las variedades mejoradas, la selección de semillas y el fomento agrícola”. Revista Agricultura Tropical 16.10 (1960): 629-635.

Guerra, José. “Campaña para aumentar la producción de maíz”. Boletín Agrícola 419 (1955): 5073-5078.

Guerra, Guillermo et al. "Maíz y millo en Colombia: situación actual y perspectivas futuras". Revista Facultad Nacional de Agronomía 25.64 (1966): 18-25.

Gutiérrez Núñez, Netzahualcóyotl. "Entre lo inesperado y lo imprevisto: la sequía y los proyectos de mejoramiento de maíz y sorgo en El Bajío, 1943-1970”, Historia Mexicana LXX, 1 (2020): pp. 215-225.

Jiménez, Mercedes. "La fundación Rockefeller y la investigación agrícola en América Latina”. Comercio Exterior 40.10 (1990): 968-975.

Lorek, Timothy. "Imagining the Midwest in Latin America: Us advisors and the envisioning of an agricultural middle class in Colombian's Cauca Valley, 19431946", The Historian 75.2 (2013), pp. 283-305.

McCook, Stuart. States of nature: science, agriculture, and environment in the Spanish Caribbean 1760-1940, Austin, University of Texas Press, 2002.

Méndez, Diana. “Semillas en tránsfuga. La Fundación Rockefeller en Colombia: escenarios de la Revolución Verde en América Latina, 1950-19672”. Pacarina del Sur 29 (2016) Sin número de páginas.

Ramírez, Hernán. "Estudio estadístico comparativo sobre dos variedades de maíz". Revista Facultad Nacional de Agronomía 6.24 (1946): 376-380

Ramírez, Ricardo. "Producción y distribución de semillas de maíz". Revista Agricultura Tropical 21.12 (1965): 853-858.

Samper, Armando. "Por una conciencia agraria". Revista Agricultura Tropical 7 (1946): 3-6.

Salgar, Lina. "El cultivo de maíz en Colombia". Revista Semillas 22-23 (2004) 2-7: Consultado en: http://www.semillas.org.co/es/el-cultivo-de-maz-en-colombia (30.05.2019). 
Suárez de Castro, Fernando. “Agricultores y técnicos". Boletín Agrícola 479 (1960): 7624-7626.

\section{Tesis, ponencias, documentos y otros}

Arboleda, Fernando. "Algunas características de maíces de alto valor nutritivo y de uso industrial", Conferencias sobre el cultivo de maíz en Colombia. Bucaramanga: ICA, 1975.

Arias, José Hernando. "Recomendaciones para el cultivo de maíz en el oriente antioqueño", Documento de trabajo ICA 14, 1984.

Arias Restrepo, Jesús y Héctor Lopera, "Diagnóstico de la producción y usos de semilla de papa, maíz y frijol en el Oriente antioqueño", Boletín de investigación 75 (1988) 27-30.

Castillo Nieto, Álvaro. La agroindustria procesadora de cereales de Colombia, factores externos e internos inductores de cambio (Tesis doctoral), Universidad Nacional de Colombia-Bogotá, 2020, pp. 81-168.

Díaz Amarís, Carlos et al., "Banco Internacional de Germoplasma de Maíz”, Boletín de Divulgación ICA, 1980.

ICA. Resumen de actividades del ICA y sus proyecciones en las zonas de Urabá y sur de Córdoba. Bogotá: ICA, 1983.

Méndez, Diana. El programa Cooperativo Centroamericano para el mejoramiento del maiz: una historia transnacional de la Revolución Verde desde Costa Rica y Guatemala, 1954-1063, (Tesis de Maestría), Instituto de Investigaciones Dr. José María Luis Mora, 2018.

Mendoza Osorio, Alejandro. "Situación de la producción de semillas en Colombia", Memorias Foro Tecnológico sobre producción de semillas. Medellín, ICA, 1989.

Osorio Saraz, Jairo et al., "Historia y presencia de la Facultad de Ciencias Agrarias de la Universidad Nacional de Colombia, sede Medellín, 1914-2017”' (Texto inédito).

Picado, Wilson. Conexiones de la Revolución Verde. Estado y cambio tecnológico en la agricultura de Costa Rica durante el periodo 1940-1980, (Tesis doctoral), Universidad de Santiago de Compostela, 2012.

Quesada, Fernando. "Desidia estatal y diplomacia filantrópica: el Programa Agrícola de la Fundación Rockefeller en Chile, 1940-1970”, en J. Morales (Comp.) Filantropía, ciencia y universidad. Nuevos aportes y análisis sociohistóricos sobre la diplomacia académica en América Latina. Santiago de Chile, Ediciones UCSH, 2018. 
Ramírez, Ricardo. "Multiplicación, certificación y distribución de semillas de maíz", IX Conferencia de del Programa de Maiz y Sorgo. Cereté: ICA, 1967.

Rivera Gómez, Antonio y Jorge Enrique Llano. "Pruebas regionales de maíz en Colombia”, Boletín de Divulgación 13 (Medellín: ICA, 1974) 22-40.

Torregroza, Manuel. "Variedades de híbridos de maíz para una alta productividad", Conferencias sobre el cultivo de maíz. Bucaramanga: ICA, 1976.

Torregroza, Manuel. "Maíz y Sorgo: dos cereales básicos de la agricultura colombiana” (Bogotá: ICA) 2-46. Consultado en: https://repository.agrosavia.co/ handle/20.500.12324/12056 (02.02.2019).

Yepes, Emilio. "El maíz y su industrialización”, IX Conferencia del programa de maíz y sorgo. Cereté, ICA, 1967.

Vera, Iván. "La Industria privada en la multiplicación y certificación de semillas mejoradas”, IX Conferencia de del Programa de Maíz y Sorgo. Cereté: ICA, 1967. 